\title{
Formation of Corrugated 2D Tin lodide Perovskites and Their Use as Lead-Free Solar Absorbers
}

\author{
Benny Febriansyah, ${ }^{[\mathrm{a}],[\mathrm{b}],[\mathrm{c}]}$ Yulia Lekina, ${ }^{[\mathrm{d}]}$ Jagjit Kaur, ${ }^{[\mathrm{e}]}$ Thomas J. N. Hooper, ${ }^{[\mathrm{f}]}$ Padinhare Cholakkal \\ Harikesh, ${ }^{[\mathrm{b}],[\mathrm{c}]}$ Ming Hui Lim, ${ }^{[\mathrm{a}]}$ Teck Ming Koh, ${ }^{[\mathrm{b}]}$ Sudip Chakraborty, ${ }^{[\mathrm{e}] *}$ Ze Xiang Shen, ${ }^{[\mathrm{b}],[\mathrm{d}] *}$ Nripan \\ Mathews, ${ }^{[\mathrm{b}],[\mathrm{g}] *}$ Jason England $^{[\mathrm{a}] *}$
}

[a] Division of Chemistry and Biological Chemistry, School of Physical and Mathematical Sciences, Nanyang Technological University, 21 Nanyang Link, Singapore 637371, Singapore.

[b] Energy Research Institute at Nanyang Technological University (ERI@N), Research Techno Plaza, X-Frontier Block Level 5, 50 Nanyang Drive, Singapore 637553, Singapore.

[c] Interdiscipinary Graduate School (IGS), 50 Nanyang Avenue, Singapore 639798 Singapore

[d] Division of Physics and Applied Physics, School of Physical and Mathematical Sciences, Nanyang Technological University, 21 Nanyang Link, Singapore 637371, Singapore.

[e] Materials Theory for Energy Scavenging (MATES) Lab, Discipline of Physics, Indian Institute of Technology Indore, Simrol, Indore 453552, India.

[f] Centre of High Field Nuclear Magnetic Resonance (NMR) Spectroscopy and Imaging, Nanyang Technological University, 21 Nanyang Link, Singapore 637371, Singapore.

[g] School of Materials Science and Engineering, Nanyang Technological University, 50 Nanyang Avenue, Singapore 639798, Singapore.

\begin{abstract}
Major strides have been made in the development of materials and devices based around low-dimensional hybrid group 14 metal halide perovskites. Thus far, this work has mostly focused upon compounds containing highly toxic $\mathrm{Pb}$, with the analogous less toxic Sn materials being comparatively poorly evolved. In response, the study herein aims to (i) provide insight into the impact of templating cation upon the structure of 2D tin iodide perovskites, and (ii) examine their potential as light absorbers for photovoltaic (PV) cells. It was discovered through systematic tuning of organic dications, that imidazolium rings are able to induce formation of (110)-oriented materials, including the first examples of " $3 \times 3$ " corrugated Sn-I perovskites. This structural outcome is a consequence of a combination of supramolecular interactions of the two endocyclic $\mathrm{N}$-atoms in the imidazolium functionalities with the $\mathrm{Sn}$-I framework and the higher tendency of $\mathrm{Sn}^{2+}$ ions to stereochemically express their $5 \mathrm{~s}^{2}$ lone pairs relative to the $6 \mathrm{~s}^{2}$ electrons of $\mathrm{Pb}^{2+}$. More importantly, the resulting materials feature very short separations between their 2D inorganic layers with iodide-iodide ( $\mathrm{I} \cdots \mathrm{I})$ contacts as small as $4.174 \AA$, which is amongst the shortest ever recorded for $2 \mathrm{D}$ tin iodide perovskites. The proximate inorganic distances, combined with the polarizable nature of the imidazolium moiety, eases the separation of photogenerated charge within the materials. This is evident from the excitonic activation energies as low as $83(10)$ meV, measured for $\operatorname{ImEA}\left[\mathrm{SnI}_{4}\right]$. When combined with superior light absorption capabilities relative to their lead congeners, this allowed fabrication of lead-free solar cells with incident photon-to-current and power conversion efficiencies of up to $70 \%$ and $2.26 \%$, respectively, which are amongst the highest values reported for pure 2D group 14 metal halide perovskites. In fact, these values are superior to the corresponding lead iodide material, which demonstrates that 2D Sn-based materials have significant potential as less toxic alternatives to their $\mathrm{Pb}$ counterparts.
\end{abstract}

\section{INTRODUCTION}

Hybrid organic-inorganic lead halide perovskites have shown remarkable promise in a range of optoelectronic applications. Most prominently, the use of the three-dimensional (3D) material (A) $\mathrm{PbX}_{3}$ (where $\mathrm{A}$ is a relatively small monocation, such as methylammonium $\left(\mathrm{MA}^{+}\right)$and formamidinium $\left(\mathrm{FA}^{+}\right)$, and $\mathrm{X}$ is bromide or iodide) as a light absorbing layer has allowed development of photovoltaic cells displaying remarkable power conversion efficiencies (PCEs) of up to $25.2 \% .^{1}$ This, combined with their solution processability, makes them highly attractive and has led to intensive study of their properties and applications. On the downside, major challenges are posed by the high toxicity of water-soluble $\mathrm{Pb}^{2+}$, which can contaminate groundwater during processing or as a consequence of module damage. $^{2}$ This has spurred investigations into replacement of $\mathrm{Pb}$ with less toxic elements, such as $\mathrm{Sn}$ or Ge. While examples of hybrid perovskites containing each of these alternatives is known, Ge halide perovskites seem less promising due to the very poor inherent chemical stability of $\mathrm{Ge}^{2+} \cdot 3-4$ On the other hand, Sn-based perovskites are more desirable due to the similarity of their electronic and optical properties to $\mathrm{Pb}$ perovskites 
and their relatively eco-friendly degradation product, $\mathrm{SnO}_{2}{ }^{5}$ Thus, concerted efforts have been made to enhance the efficiency and stability of tin halide-based $3 \mathrm{D}$ perovskites via a variety of approaches, including utilization of antioxidants, ${ }^{6} 7$ reducing agents, ${ }^{89}$ and mixed-cation compositions. ${ }^{10}{ }^{11}$ This has resulted in solar cell devices with certified PCEs of over $10 \%$ that can maintain more than $90 \%$ of their initial efficiency upon storage or after operation at the maximum power point for over 1000 hours. ${ }^{12} 1314$ However, while numerous research groups have contributed to development of $3 \mathrm{D}(\mathrm{A}) \mathrm{SnX} \mathrm{X}_{3}$ perovskites for use in photovoltaic applications, the number of publications reporting the development and fundamental properties of new Snbased materials, particularly those of lower dimensionalities, remain relatively small.

Two-dimensional (2D) hybrid metal halide perovskites possessing the general chemical formulae $\left(\mathrm{RNH}_{3}\right)_{2} \mathrm{BX}_{4}$ and $\left(\mathrm{NH}_{3} \mathrm{RNH}_{3}\right) \mathrm{BX}_{4}$ ( $\mathrm{R}$ corresponds to an organic functional group, $\mathrm{B}$ a group 14 metal dication, and $\mathrm{X}$ a halide) are derived from their 3D congeners by slicing the inorganic lattice along specific crystallographic axes (e.g., the (100)- or (110)-planes). ${ }^{15-16}$ This can be induced through incorporation of moderately-sized organic cations, such as the omnipresent phenylethylammonium $\left(\mathrm{PEA}^{+}\right)$and 1-butylammonium $\left(\mathrm{BA}^{+}\right)$ions. The advantages of reduced dimensionality are multifold. First, the incorporation of inherently more hydrophobic organic cations grants improved intrinsic stability against degradation by moisture and oxygen. ${ }^{17-18}$ In addition, the larger formation energy of the low-dimensional inorganic lattices, ${ }^{19-20}$ combined with the relatively bulky organic species, renders the materials less prone to ionic migration and, thereby, reduces their electrical instability. Last but not least, it affords significant room for materials exploration and engineering. This is because the size constraints imposed on the organic cations by 3D perovskite formation (typically assessed by Goldschmidt's tolerance factor) are no longer relevant. ${ }^{21-22}$

Being initially considered ill-suited for PV applications due to electronic and quantum confinement, ${ }^{23-24}$ molecular engineering of the organic cations that template $2 \mathrm{D}$ inorganic lattice formation has led to tremendous advancements in the PCEs of solar cells based on this class of materials. Several exemplary works are worthy of mention. First is the demonstration by Stupp and co-workers ${ }^{17}$ of enhanced out-of-plan conductivity in 2D perovskites through the incorporation of suitable conjugated organic spacers (e.g., pyrene and perylene), which resulted in pure $2 \mathrm{D}$ perovskite solar cells with a PCE of $1.38 \%$. The second one was reported by our group, ${ }^{25}$ wherein we used compact pyridinium and imidazolium dications to template 2D lead iodide perovskites featuring reduced inter-octahedral distortion and inorganic interlayer separation. This allowed PCEs of up to $1.83 \%$ to be achieved. Through further fine-tuning of the inorganic lattice inter-octahedral geometry and layer separation using the 2cyanoethan-1-aminium (3-APN) templating cation, and energy level alignment within the device, Wang and co-workers were very recently able to report a highly efficient pure 2D perovskite solar cell possessing a PCE of $3.39 \% .^{18}$

The aforementioned examples of PV devices incorporating 2D perovskite solar absorbing materials are all $\mathrm{Pb}$-based. Unfortunately, comprehensive studies dedicated to the synthesis and characterization of less toxic 2D tin halide perovskites are comparatively rare. More crucially, as far we are aware, there has only been one report of a PV device using a pure 2D halostannate as a solar absorber. ${ }^{26}$ The material in question, $\mathrm{Bn}_{2}\left[\mathrm{SnI}_{4}\right](\mathrm{Bn}=$ benzimidazolium $)$, afforded a device efficiency of around $2.3 \%$. This suggests that these materials have promise, but further examples are required to verify this and provide insight into the molecular design principles that control 2D tin halide lattice structure. As can be seen from their Pb-based counterparts, lattice structure controls photophysical properties of metal halide perovskites, so understanding how the can be tailored is of critical importance for the development of devices with high photovoltaic efficiency.

Most 2D halostannates reported thus far are of the (100)-oriented type, with more than 50 having been documented in the Cambridge Structural Database. Therein, the $\left[\mathrm{SnX}_{6}\right]^{4-}$ octahedra corner-share their four equatorial vertices and the remaining two axial halides are terminally bound. This affords "flat" inorganic layers. On the other hand, corrugated (110)-oriented structures, which additionally contain $\left[\mathrm{SnX}_{6}\right]^{4-}$ octahedra possessing two cis-oriented terminally-bound halides, are much rarer. In fact, we are aware of only 2 examples, both iodostannates, having been published thus far. The first, reported in 1999 by Guloy and co-workers, ${ }^{27}$ incorporated the dication $\left[\mathrm{NH}_{3}\left(\mathrm{CH}_{2}\right)_{5} \mathrm{NH}_{3}\right]^{2+}$ as a template; and the second, disclosed 17 years later by Kanatzidis and co-workers, ${ }^{28}$ used doubly-protonated histamine $\left(\mathrm{HA}^{2+}\right)$. Both of these compounds, $\alpha-$ $\mathrm{NH}_{3}\left(\mathrm{CH}_{2}\right)_{5} \mathrm{NH}_{3}\left[\mathrm{SnI}_{4}\right]$ and $\alpha-\mathrm{HA}\left[\mathrm{SnI}_{4}\right]$, feature " $4 \times 4$ " corrugated structures, where " $\mathrm{n} \times \mathrm{n}$ " refers to the number $(\mathrm{n})$ of contiguous Sn octahedra comprising each ridge. Thus, systematic structural and photophysics investigations of (110)-oriented 2D tin halide perovskites are almost non-existent. By extension, we are uncertain about how the structure of organic cations influences formability of the lattice and how this impacts the optoelectronic properties of these materials.

Spurred by these considerations, we utilized the ditopic organic dication 1-(2-ammonioethyl)-1H-imidazol-3-ium $\left(\mathrm{ImEA}^{2+}\right)$ to template the formation of the $2 \mathrm{D}$ tin iodide perovskite $\mathrm{ImEA}_{\left[\mathrm{SnI}_{4}\right] \text {. ImEA }}{ }^{2+}$ was selected because we have previously shown that it is able to selectively induce formation of rare corrugated lead halide structures. ${ }^{25,29}$ In addition, relatively efficient pure 2D lead-based perovskite solar cells with good current generation were obtained using this dication. ${ }^{25}$ As such, it not only serves as an excellent platform for investigation of the formability of (110)-oriented structural motifs, along with their accompanying optoelectronic properties, but also enables a direct comparison of the impact of $\mathrm{Sn}$ versus $\mathrm{Pb}$ upon the photovoltaic performance of $2 \mathrm{D}$ perovskites to be made.

\section{RESULTS AND DISCUSSION}

Imidazolium cores and their role in formation of corrugated structures. To synthesize the target compound, $\operatorname{ImEA}(\mathrm{I})_{2}$ was combined with $\mathrm{SnI}_{2}$ in hot hydroiodic acid under an inert atmosphere. Slow cooling of the solution led to formation of dark maroon colored crystals. X-ray crystallographic analysis of the compound formed, ImEA[SnI 4 , yielded the structure displayed in Figure 1. (Crystallographic and structure refinement data appear in Tables S1-S3.) As observed in the corresponding $\mathrm{Pb}-\mathrm{I}$ compound, a "3 3 3" (110)-oriented 2D structure, composed of alternating inorganic and organic monolayers, was observed. The distances between its constituent inorganic layers are very short, which can be attributed to the compact nature of the dication and flexibility of the ammonioethyl pendant. Indeed, the shortest $\mathrm{I} \cdots \mathrm{I}$ contacts in this structure, of $4.174 \mathrm{~A}^{\circ}$, are amongst the shortest ever recorded for 2D tin iodide perovskites. For comparison, the flexible organic cations $N^{1}, N^{1}, N^{1}$ trimethylethane-1,2-diaminium, ${ }^{\mathbf{3 0}}$ 1,5-pentanediammonium, ${ }^{31}$ 
and 1-butylammonium ${ }^{29}$ impart closest I $\cdots$ I contacts of 4.186, 4.587, and $8.668 \AA$, respectively. Meanwhile, the more rigid cations biimidazolium, ${ }^{32}$ benzodiimidazolium, ${ }^{\mathbf{2 6}}$ and benzimidazolium $^{33}$ yield respective I $\cdots$ I closest contacts of $4.444,4.855$, and $8.077 \AA$.
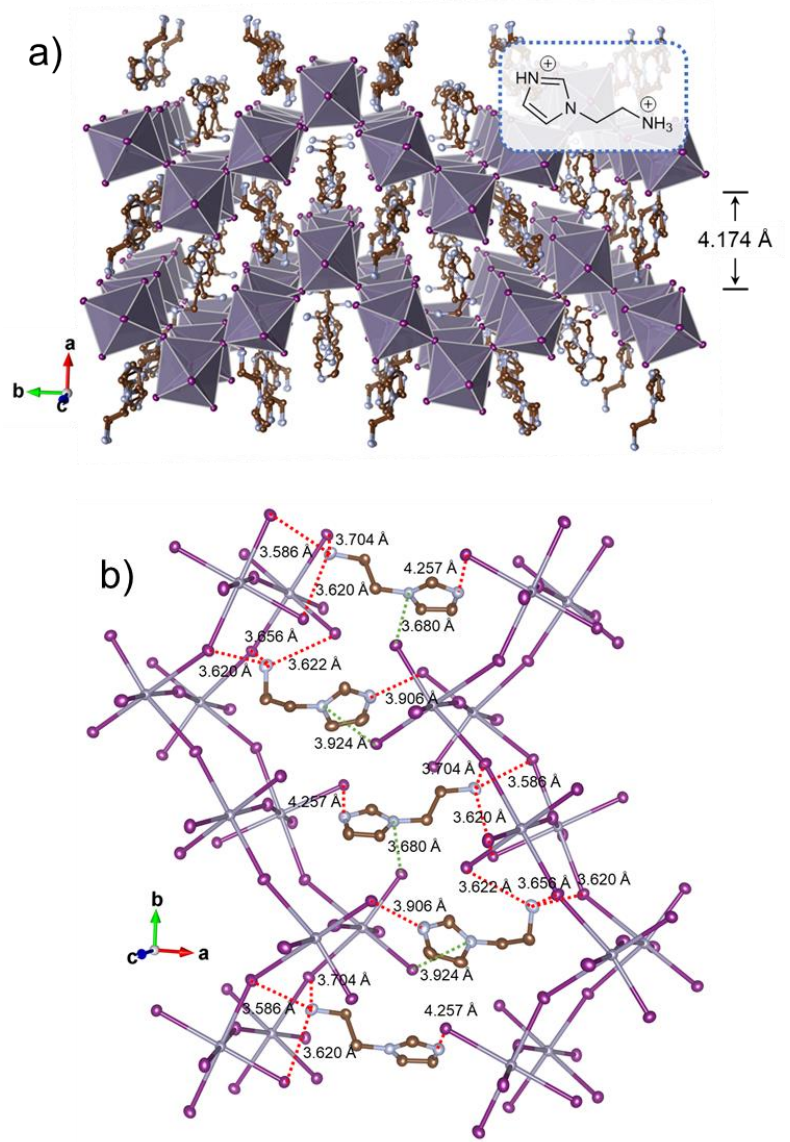

Figure 1. a) X-ray crystal structure of " $3 \times 3$ " (110)-oriented $2 \mathrm{D}$ perovskite $\mathrm{ImEA}\left[\mathrm{SnI}_{4}\right]$. The inset shows the molecular structure of $\operatorname{ImEA}^{2+}$. b) X-ray crystal structure of $\operatorname{ImEA}\left[\mathrm{SnI}_{4}\right]$ highlighting the closest contacts between the primary ammonium and imidazolium $\mathrm{NH}^{+} \mathrm{N}$-atoms of $\mathrm{ImEA}^{2+}$ and the bridging/terminal $\mathrm{I}^{-}$ions of the iodostannate lattice (dashed red lines). The closest contacts between the alkylated endocyclic $\mathrm{N}$ atoms of $\mathrm{ImEA}^{2+}$ and terminally bound $\mathrm{I}^{-}$ions are depicted using dashed green lines. Lavender, purple, brown, and blue spheroids represent $\mathrm{Sn}, \mathrm{I}, \mathrm{C}$, and $\mathrm{N}$ atoms, respectively. $\mathrm{H}$ atoms are omitted for clarity. Ellipsoids are shown at $50 \%$ probability.

Each asymmetric unit of $\left.\mathrm{ImEA}_{[} \mathrm{SnI}_{4}\right]$ contains two inequivalent ImEA ${ }^{2+}$ dications (Figure S1), which differ in terms of conformation and interactions with the iodostannate lattice. Hbonding interactions between the primary ammonium and imidazolium $\mathrm{N}-\mathrm{H}$ groups and their neighboring iodide ions $(\mathrm{N} \cdots \mathrm{I}$ contacts ranging from 3.586 to $4.257 \AA$; Figure 1b) are observed in both conformations. In addition, the structure features coulombic interactions between the alkylated endocyclic $\mathrm{N}$-atoms of the ImEA ${ }^{2+}$ dications and terminally-bound iodides that are oriented perpendicular to the plane of the imidazolium ring (N... I contacts of 3.680 and $3.924 \AA$ ).

Interestingly, attempts to induce similar (110)-oriented 2D tin iodide structures using templating dications comprised of pyridinium substituted at various positions by 2-ethylammonium pendant groups were unsuccessful. In all cases, (100)-type 2D structures are obtained (Figures 2a-d). Although the larger ring size of pyridinium may play a role in determining the inorganic architecture, we believe the deciding factor is the additional $\mathrm{H}$-bonding interaction with the imidazolium ring, which is a consequence of having two endocyclic $\mathrm{N}$-atoms. The extra intermolecular interactions that this provides are sufficient to stabilize the, seemingly, less stable corrugated structure. This notion is supported by the observation that isomeric imidazolium-based dication 2-(2-ammonioethyl)-1H-imidazol-3-ium (2-ImEA), also, templates formation of a " $3 \times 3$ " (110)-oriented 2D tin iodide perovskite (Figure 2f). Therein, the observed N...I contacts, ranging from 3.457 to $3.685 \AA$, are even shorter than those observed in $\operatorname{ImEA}\left[\mathrm{SnI}_{4}\right]$ (see Figure $\mathbf{S 2}$ for more details).

We sought to corroborate this conclusion by examining the structure of the previously reported compound $\mathrm{HA}\left[\mathrm{SnI}_{4}\right]$ (see Figure 2g) ${ }^{28}$ However, it has not been deposited into the Cambridge Structural Database. In response, we proceeded to synthesize this material and solve its single crystal X-ray structure. Under our synthetic conditions, it exists exclusively in a " $4 \times$ 4" (110)-type orientation and is stable for months both in the mother liquor and dry, as long as the inert atmosphere is provided. This is surprising given that conversion to a thermodynamically stable (100)-oriented phase was reported to occur upon leaving $\mathrm{HA}\left[\mathrm{SnI}_{4}\right]$ in the crystallization mother liquor. ${ }^{28}$ Regardless, all of the ethylammonium-substituted imidazolium dications are found to template corrugated iodostannate motifs, while their pyridinium counterparts yield flat lattices.

Stereochemical activity of $\mathrm{Sn}(\mathrm{II})$ and $\mathrm{Pb}(\mathrm{II}) \mathrm{s}$ orbital electrons. The preceding structural trends do not hold true for the corresponding iodo- and bromoplumbates. Instead, corrugated $2 \mathrm{D}$ perovskites were obtained only for $\mathrm{ImEA}^{2+}$ (Figures $\mathbf{S 3}$ and S4), with the hybrids templated by $2-\mathrm{ImEA}^{2+}$ and $\mathrm{HA}^{2+}$ adopting (100)-type orientations..$^{25,29,34-35}$ Thus, in addition to the supramolecular interactions between their constituent organic and inorganic components, it appears that the composition of the metal halide framework is also a determining factor in whether (110)-oriented structures form. Comparison of trends in the metal halide bond lengths and displacement of the metal ions from the centre of their pseudo-octahedral coordination spheres for a series of similarly templated $\mathrm{Pb}$ and $\mathrm{Sn}$ halides shed light on the origin of these observations.

It is clear from Figure 3 (see Tables S4-S24 for the complete list of data) that the distribution of metal halide bond distances in the iodostannate and bromoplumbate lattices incorporating the dications studied herein are, in general, much broader than their iodoplumbate congeners. Correspondingly, the displacements of the metal ions from the centroids of the six halides coordinated to them (i.e., the centres of their octahedra) are, on the whole, the largest for the iodostannates and smallest for the iodoplumbates (Tables 1 and S25). The off-centre displacements for the bromoplumbates are intermediate between the two groups of materials. These structural trends are consistent with expectations for stereochemically active metal $\mathrm{ns}^{2}$ electron pairs, which arise from pseudo- or second-order Jahn-Teller effects. ${ }^{36-37}$ 38-41 This is associated with mixing of metal $s$ and $p$ orbital character (i.e., orbital hybridization), which is mediated by bonding with the halide anions. Relativistic effects render the $\mathrm{Pb} 6 \mathrm{~s}^{2}$ electrons less available for overlap with the halide $\mathrm{p}$ orbitals than the $\mathrm{Sn} 5 \mathrm{~s}^{2}$ electrons. Thus, mixing with the $\mathrm{Pb} 6 \mathrm{p}$ orbitals is comparatively small and, consequently, there are 

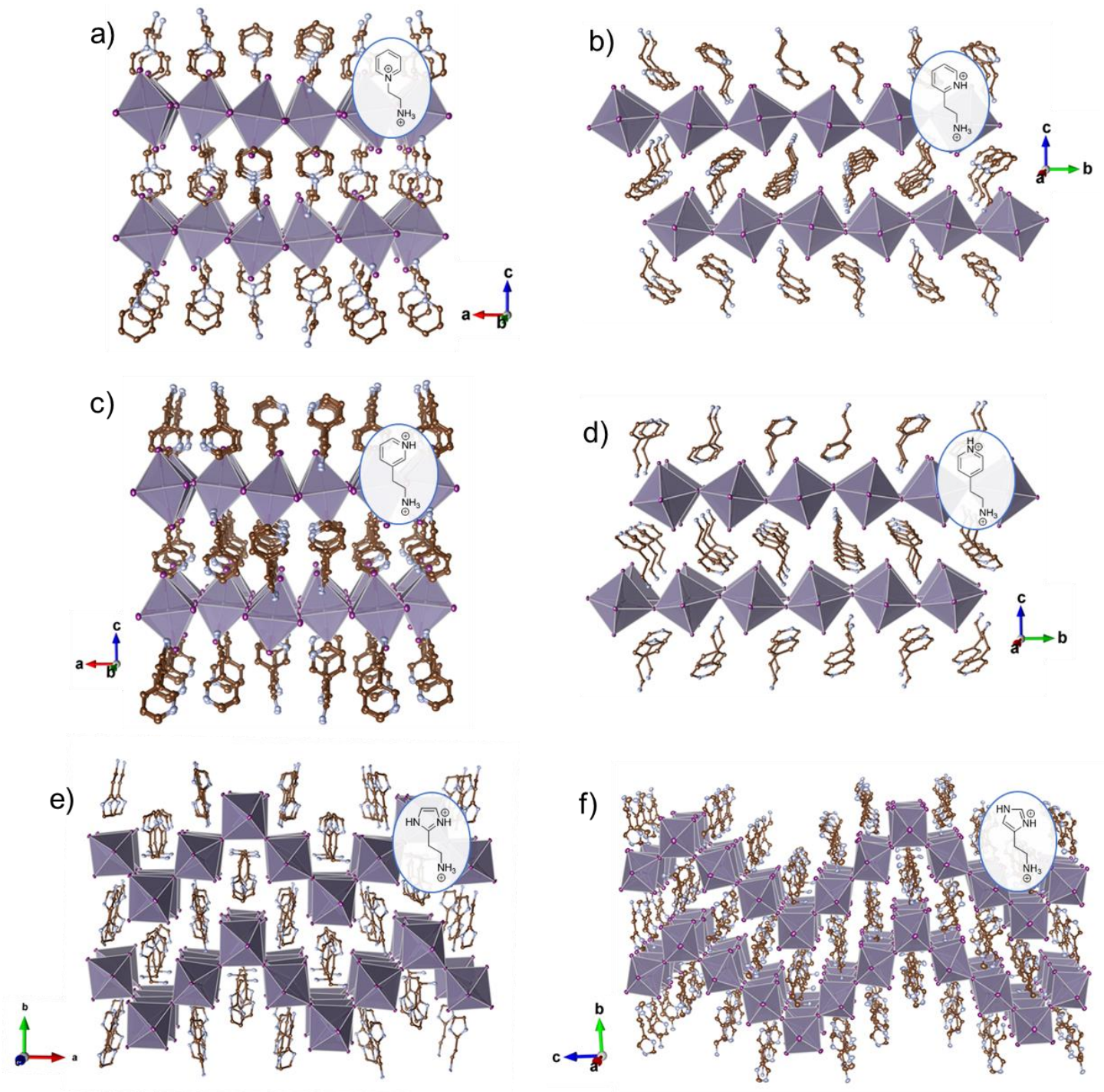

Figure 2. X-ray crystal structures of the pyridinium-based (100)-oriented 2D tin iodide perovskites a) PyrEA[SnI 4 , b) 2-PyrEA[SnI 4 , c) 3-PyrEA[SnI 4 , and d) 4-PyrEA[SnI 4 and their imidazolium-based (110)-oriented congeners, e) 2-ImEA[SnI 4 , and f) HA[SnI $\mathrm{Sm}_{4}$ Lavender, purple, light brown and light blue spheroids correspond to $\mathrm{Sn}, \mathrm{I}, \mathrm{C}$ and $\mathrm{N}$ atoms, respectively. $\mathrm{H}$ atoms are omitted for clarity. Thermal ellipsoids are shown at $50 \%$ probability. The insets show the aryl component of the templating dications.

limited structural distortions. ${ }^{32,42-44}$ Similarly, more electronegative anions have better overlap with the metal ns orbitals and leads to them displaying enhanced stereochemical activity. ${ }^{45-47}$

Of the series of iodostannates described in this manuscript, the largest off-center displacements are seen for the Sn centres occupying the ridges of the $3 \times 3$ (110)-oriented lattices (Table S25). They range from $0.237-0.310 \AA$, whereas the off-centre displacements in the (100) iodostannates range from 0.061 $0.196 \AA$. The ridge-occupying octahedra of the (110) materials are comprised of two cis-oriented terminally bound iodides $\left(\mathrm{I}_{\mathrm{t}}\right)$, for which the $\mathrm{Sn}-\mathrm{I}$ bond lengths are unusually short (2.9534(9) and 2.9607(9) $\AA$ in $\left.\operatorname{ImEA}\left[\mathrm{SnI}_{4}\right]\right)$, plus four iodides that bridge $(\mu-\mathrm{I})$ to other $\mathrm{Sn}$ centres (Table $\mathbf{S 4})$. The $\mathrm{Sn}-\mathrm{I}$ distances for the two $\mu$-I trans to the $\mathrm{I}_{\mathrm{t}}$ are significantly elongated (3.3388(9) and 3.417(9) $\AA$ in $\left.\operatorname{ImEA}\left[\mathrm{SnI}_{4}\right]\right)$. This arrangement is a consequence of the stereochemically active $n s^{2}$ pair of electrons being oriented towards the elongated bonds. The metal ions in the (100)oriented compounds tend to display more $C_{3}$-symmetric distortions, with three facially-oriented elongated $\mathrm{Sn}$-I bonds. Although the difference in length is often quite severe along one axis (e.g., $\mathrm{Sn}-\mathrm{I}_{\mathrm{t}}$ in PyrEA[SnI $\left.{ }_{4}\right]=2.9558(5)$ and 3.4835(6) $\AA$; Table S7), the distortions are usually much less extreme than the corresponding (110) iodostannates.

The general trends in structural distortion described for the iodostannates holds true for their iodoplumbate congeners. In contrast, the $\mathrm{Pb}^{2+}$ ions in the (110)-oriented compound ImEA $\left[\mathrm{PbBr}_{4}\right]$ exhibit minimal off-centre displacements of $0.056 \AA$ (Table S5). This can be attributed to it possessing $2 \times$ 2 corrugation, rather than the $3 \times 3$ (or $4 \times 4$ ) structures seen in the other (110) compounds. In the $2 \times 2$ corrugated system, the $\mu$-Br halides ions are directly shared between ridge-occupying octahedra, which limits the possible extent of $\mathrm{Pb}-\mathrm{Br}$ bond elongation/weakening.

It should be noted that regardless of whether they possess (110)- or (100)-oriented structures, the metal halide lattices accompanying imidazole-based templating dications $\operatorname{ImEA}^{2+}$, 


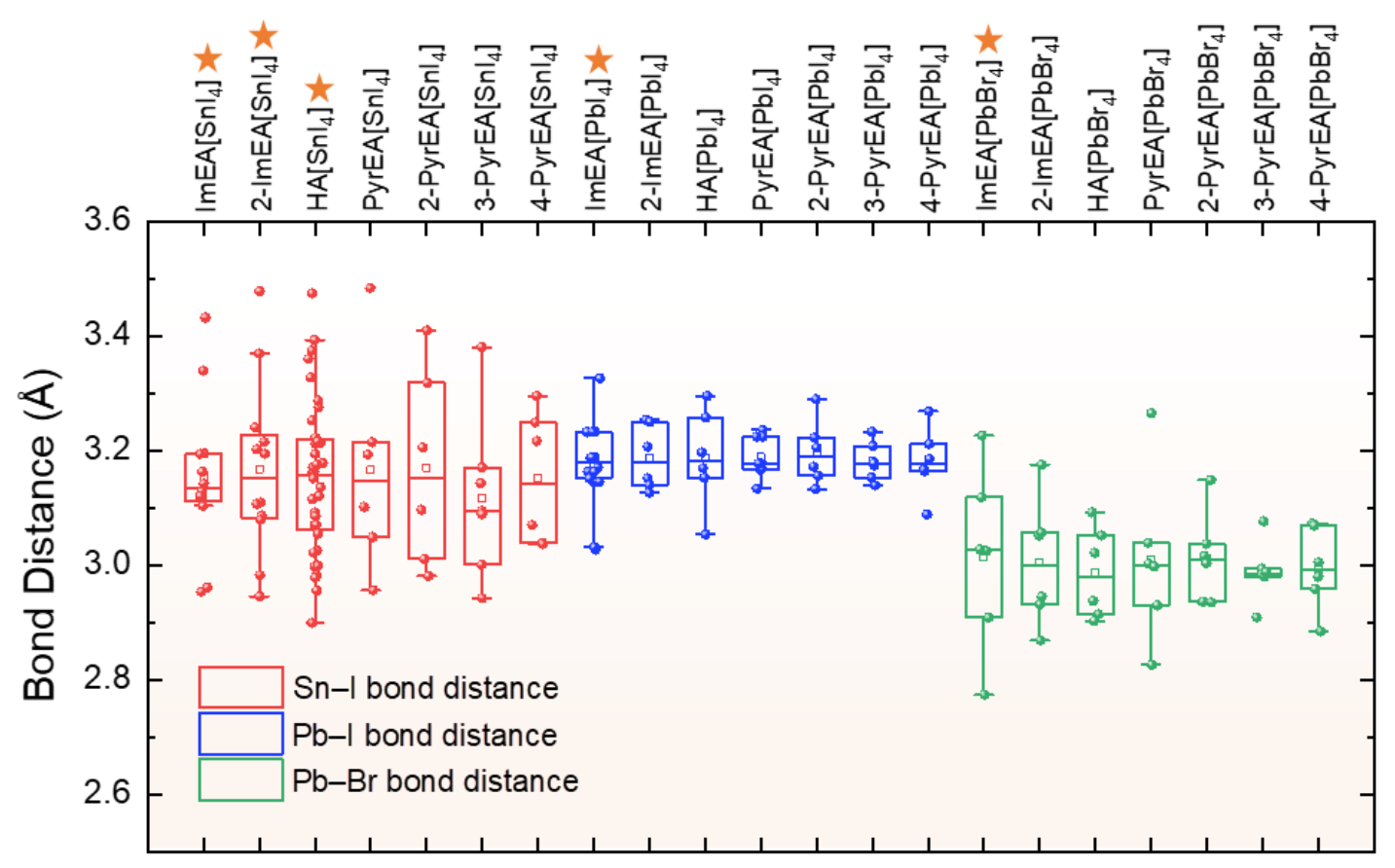

Figure 3. Comparison of the bond length distributions in the 2D $\mathrm{Pb}-\mathrm{I}, \mathrm{Sn}-\mathrm{I}$ and $\mathrm{Pb}$ - $\mathrm{Br}$ perovskites templated by the series of organic dications ImEA, 2-ImEA, HA, PyrEA, 2-PyrEA, 3-PyrEA, and 4-PyrEA. Stars indicate corrugated structures. See Figure 2 for the molecular structures of the corresponding dications. The depicted bond lengths are listed in Tables S4-S24.

Table 1. Off-centre displacements $(\AA)$ for $2 \mathrm{D}$ group 14 metal halide perovskites, $\mathrm{A}\left[\mathrm{MX}_{4}\right]$, discussed in this study. ${ }^{\mathrm{a}}$

\begin{tabular}{|c|c|c|c|}
\hline \multirow{2}{*}{$\begin{array}{c}\text { Templating } \\
\text { dication, } \mathrm{A}^{2+}\end{array}$} & \multicolumn{3}{|c|}{ Off-centre displacement $(\AA)$} \\
\hline & $\mathrm{A}\left[\mathrm{SnI}_{4}\right]$ & $\mathrm{A}\left[\mathrm{PbI}_{4}\right]$ & $\mathrm{A}\left[\mathrm{PbBr}_{4}\right]$ \\
\hline $\operatorname{ImEA}^{2+}$ & 0.278 & 0.297 & 0.056 \\
\hline $2-\operatorname{ImEA}^{2+}$ & 0.266 & 0.153 & 0.215 \\
\hline $\mathrm{HA}^{2+}$ & 0.310 & 0.159 & 0.166 \\
\hline PyrEA $^{2+}$ & 0.189 & 0.059 & 0.186 \\
\hline 2-PyrEA ${ }^{2+}$ & 0.196 & 0.105 & 0.087 \\
\hline $3-\mathrm{PyrEA}^{2+}$ & 0.102 & 0.030 & 0.078 \\
\hline 4-PyrEA ${ }^{2+}$ & 0.061 & 0.041 & 0.057 \\
\hline
\end{tabular}

${ }^{a}$ The highest value is selected in the case of structures containing multiple geometrically distinct $\left[\mathrm{MX}_{6}\right]^{2-}$ octahedra. See Table S25 for complete list of values.

2-ImEA ${ }^{2+}$ and $\mathrm{HA}^{2+}$ generally display greater structural distortions than their pyridine-based dication templated analogues. This is a result of the earlier discussed supramolecular interactions between the organic and inorganic components and is a testament to their importance in controlling the micro-structure of the lattice. We postulate that once the level of distortion reaches a certain threshold, the (110)-oriented lattices become favored relative to (100) structures. In the case of iodoplumbates and bromoplumbates, this is seen only for ImEA ${ }^{2+}$. As the $5 \mathrm{~s}^{2}$ electrons of stannates are more stereochemically active than the $6 s^{2}$ electrons of plumbates, the threshold is more easily passed and (110)-oriented lattices are obtained for a wider array of templating cations. In other words, we would expect (110)oriented 2D structures to be more common for stannates than plumbates. Furthermore, it is likely that more electronegative halides will further enhance or exaggerate this effect.
NMR spectra of (110)- vs (100)-oriented structures. The difference between the coordination environments of $\mathrm{Sn}$ in ImEA[SnI $]$ and the (100)-oriented 2D iodostannates, exemplified here by 3-PyrEA[SnI 4 ] (3-PyrEA ${ }^{2+}=3$-(2-ammonioethyl)pyridin-1-ium), can be discerned in powdered samples using static solid-state NMR (SSNMR) measurements. In particular, the static ${ }^{119} \mathrm{Sn}$ SSNMR spectrum of 3-PyrEA[SnI 4 contains a single resonance at $-135 \mathrm{ppm}$, whereas that of ImEA[SnI 4 contains two overlapping peaks (Figures 4a-b). Gaussian fitting of the latter allows deconvolution into two resonances of equal intensity, centred at -23 and $-327 \mathrm{ppm}$. These observations are in accordance with the X-ray crystal structures of these compounds. As with all (100)-oriented structures, 3PyrEA $\left[\mathrm{SnI}_{4}\right]$ contains only a single type of $\mathrm{Sn}$ coordination environment. In other words, all of the $\mathrm{Sn}$ ions are equivalent. However, the $\mathrm{Sn}$ ions in $\operatorname{ImEA}\left[\mathrm{SnI}_{4}\right]$ alternate across a sheet (along the b and c axes) between having two terminally-bound iodide ions cis and trans to one another. These arrangements correspond to $\mathrm{Sn}$ ions at the vertices and those on the flat slopes between them, respectively.

Variations in the environments of the organic countercations in $\mathrm{ImEA}\left[\mathrm{SnI}_{4}\right]$ and 3-PyrEA[SnI 4$]$ are also apparent in their magic angle spinning (MAS) ${ }^{13} \mathrm{C}$ SSNMR spectra (Figures 4cd). Each chemically distinct carbon atom in $3-\mathrm{PyrEA}^{2+}$ yields a single resonance, but peaks indicative of two inequivalent dications are observed for $\operatorname{ImEA}^{2+}$ (i.e., double the number). This is consistent with the numbers of distinct dications in the X-ray structures of their respective iodostannates (Figure S5).

Photophysical properties of ImEA[SnI 4 . Previously, it has been demonstrated that interlayer separation in 2D perovskites plays a critical role in determining photocurrent generation in the corresponding solar cell devices. In particular, short perpendicular contacts favour superior charge transport. ${ }^{34,48}$ As a 

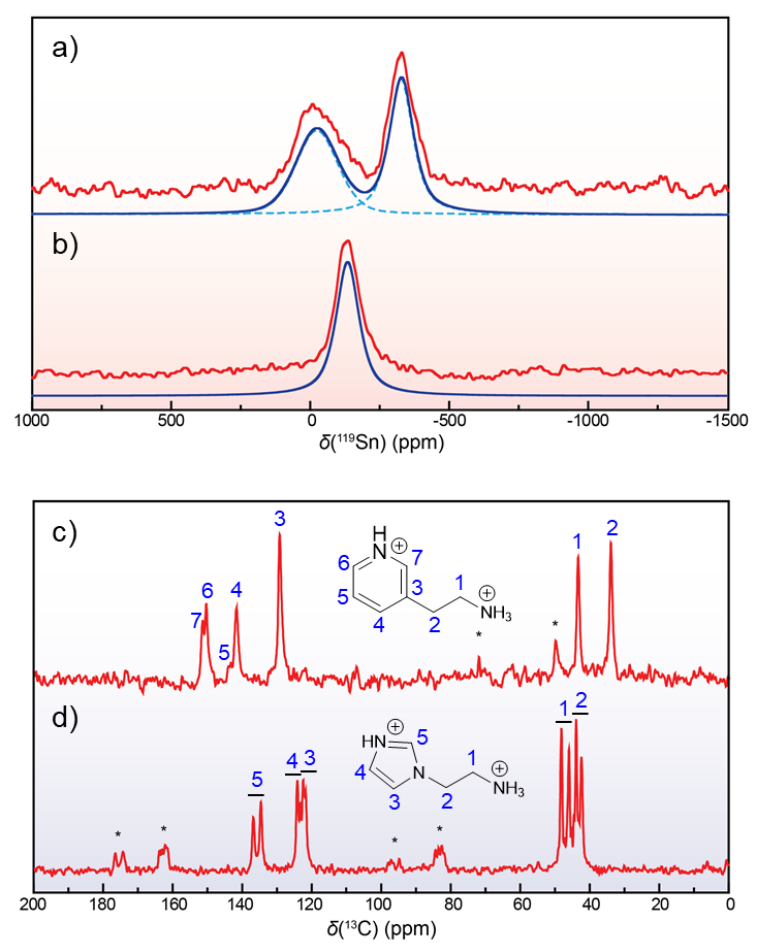

Figure 4. Room temperature, static ${ }^{119} \mathrm{Sn}$ solid-state (SS) NMR spectra of a) " $3 \times 3$ " (110)-oriented $\left.\operatorname{ImEA}_{\mathrm{SnI}}\right]$ and b) (100)oriented 3-PyrEA[SnI 4 . Experimental data, total simulated line-shapes, and deconvoluted simulated resonances are depicted using red, blue and dashed sky blue lines, respectively. Room temperature magic angle spinning (MAS) ${ }^{13} \mathrm{C}$ SSNMR spectra of c) 3-PyrEA[SnI 4 and d) ImEA[SnI 4 .

consequence, the photophysical properties of $\left.\mathrm{ImEA}_{[\mathrm{SnI}}\right]$ were further investigated to assess its suitability for photovoltaic applications. The UV-Vis absorption spectrum of $\operatorname{ImEA}\left[\mathrm{SnI}_{4}\right]$ is presented in Figure 5a (blue curve) and, in analogy to other 2D iodostannates, ${ }^{26,}{ }^{49}$ the band centred at $\sim 580 \mathrm{~nm}$ can be attributed to excitonic absorptions of the tin iodide lattice. As observed for 2D iodoplumbates, the excitonic transition of $\operatorname{ImEA}\left[\mathrm{SnI}_{4}\right]$ is blue-shifted relative to those of (100)-oriented 2D tin iodide perovskites, which range from $600 \mathrm{~nm}$ to 700 $\mathrm{nm} .^{20,26}$ This can be attributed to poorer $\mathrm{Sn} 5 \mathrm{~s}$ and I 5 p orbital overlap in the corrugated sheets relative to (100) oriented structures..$^{\mathbf{2 5}, \mathbf{5 0 - 5 1}}$ Nonetheless, the excitonic transition of $\operatorname{ImEA}\left[\mathrm{SnI}_{4}\right]$ is, of course, bathochromically-shifted with respect to that of the corresponding isostructural $\mathrm{Pb}$ compound $\operatorname{ImEA}\left[\mathrm{PbI}_{4}\right] .^{25}$ The lower band gap in the Sn compound, that this equates to, is a consequence of the lower electronegativity and smaller size of $\mathrm{Sn}^{2+}$ relative to $\mathrm{Pb}^{2+}$.52-54 This is consistent with the DFT calculated optical absorption spectra (Figure S6) and total density of states (Figure S7) of ImEA $\left[\mathrm{SnI}_{4}\right]$ and $\operatorname{ImEA}\left[\mathrm{PbI}_{4}\right]$, wherein the former exhibits extended visible light absorption and a lower band gap compared with the latter.

Room temperature excitation of $\operatorname{ImEA}\left[\mathrm{SnI}_{4}\right]$ at $573 \mathrm{~nm}$ yields a photoluminescence (PL) emission spectrum containing a moderately intense, asymmetric peak at $611 \mathrm{~nm}$, with a full width at half maximum (fwhm) of $c a .95 \mathrm{~nm}(300 \mathrm{meV})$, and a Stokes shift of ca. $109 \mathrm{meV}$ (Figure 3a, red curve). As shown in Figure S8, the CIE coordinates of the emission are (0.64, 0.36), which corresponds to red light emission. As might be anticipated for a (110)-oriented inorganic lattice, the observed PL signature is broader than seen for conventional (100)-oriented congeners. For instance, BA- and PEA-based tin iodide perovskites exhibit PL peaks with fwhm of less than $40 \mathrm{~nm} \cdot{ }^{55-56}$ In the case of $\mathrm{Pb}$-based materials, these trends in emissive behaviour have been hypothesized to arise from self-trapped excitons (STEs), with the greater fwhm and Stokes shift values in the more distorted (110) structures being a consequence of enhanced exciton-phonon coupling. ${ }^{50,57}$ (See Table S26 and accompanying text for detailed analysis of the structural distortions of ImEA[SnI $\left.{ }_{4}\right]$ and selected Sn-I compounds.) When $\operatorname{ImEA}\left[\mathrm{SnI}_{4}\right]$ is excited with laser power ranging from 0.017 to $5 \mu \mathrm{W}$, PL intensity increases linearly and shows no signs of saturation (Figures 5b-c). This supports the notion that emission arises from STEs and not from permanent defects.

The good visible light absorption capability of $\operatorname{ImEA}\left[\mathrm{SnI}_{4}\right]$, which spans up to $650 \mathrm{~nm}$, prompted us to study the behaviour of its photogenerated charge carriers. To that end, we performed temperature-dependent PL measurements between 80 and 293 $\mathrm{K}$. The resulting spectra are presented in Figure 5d, while the PL spectra with normalized emission intensities appear in Figure S9. Plotting emission intensity against the inverse of temperature and fitting the data to the Arrhenius equation (Figure 5e) provides an estimated activation energy $\left(E_{a}\right)$ of $83(10) \mathrm{meV}$. Very few $E_{a}$ 's have been reported for 2D iodostannates, which would seemingly limit the context available for this value. However, the aforementioned value is essentially identical to the $E_{a}$ of $c a .94 \mathrm{meV}$ previously measured for its lead analogue ImEA $\left[\mathrm{PbI}_{4}\right] .{ }^{25}$ The same can also be said for $(\mathrm{PEA})_{2}\left[\mathrm{SnI}_{4}\right]$ and $(\mathrm{PEA})_{2}\left[\mathrm{PbI}_{4}\right]$, which have respective $E_{a}$ 's of $c a .190^{58}$ and 220 $\mathrm{meV},{ }^{59}$ and $3 \mathrm{D} \mathrm{Sn}-\mathrm{I}$ and $\mathrm{Pb}-\mathrm{I}$ perovskites $\left(E_{a}\right.$ values ranging from 10 to $20 \mathrm{meV}){ }^{54,60}$ Given that $2 \mathrm{D}$ iodoplumbates templated by alkyl ammonium cations typically have $E_{a}$ values above $300 \mathrm{meV}$, while those of more polarizable aromatic cations are around $200 \mathrm{meV},{ }^{\mathbf{5 9 ,} 61}$ it can be inferred that the $E_{a}$ meas-

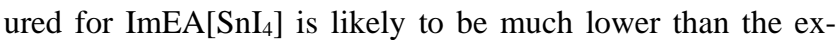
pected for a typical Sn-based 2D perovskite. We believe that this stems from ImEA[SnI $]$ possessing a combination of very short $\mathrm{Sn}-\mathrm{I}$ layer separations and relatively highly polarizable aromatic dications. These factors, effectively, render the perovskite more "3D-like" in character.

DFT calculations. To obtain further insight into the electronic structure of $\left.\operatorname{ImEA}_{\mathrm{SnI}}\right]$ and how it compares with that of ImEA[PbI $\left.{ }_{4}\right]$, we performed density functional theory (DFT) calculations. The total and projected density of states (DOS and PDOS, respectively) for these two compounds are given in Figures 6 and S7, respectively. The accuracy of the electronic structures obtained is evidenced by the excellent agreement between their respective DFT simulated (Figure S6) and experimentally measured UV-Vis spectra. As seen in other Sn-based $2 \mathrm{D}$ perovskites, ${ }^{48}$ the primary contributor to the valence band maximum $(\mathrm{VBM})$ in $\mathrm{ImEA}\left[\mathrm{SnI}_{4}\right]$ are antibonding combinations of the $\mathrm{Sn} 5 \mathrm{~s}^{2}$ and I $5 \mathrm{p}$ orbitals, with the latter being dominant. From the projected density of states, it is clear that orbital mixing introduces Sn $5 p$ character into this interaction. This equates to orbital hybridization and results in stereochemical activity of the $\mathrm{Sn} 5 \mathrm{~s}^{2}$ lone pair. The near edge of the valence band is comprised mostly of fully occupied non-bonding I 5p orbitals ( $\mathrm{ca}$. $1.5 \mathrm{eV}$ ) and below that there are bonding overlaps between the 5 p orbitals of iodide and $\mathrm{Sn}(\mathrm{ca}$. $-3 \mathrm{eV})$. The anti-bonding components of the latter, which are metal dominated, are the primary contributors to the conduction band minimum (CBM). 

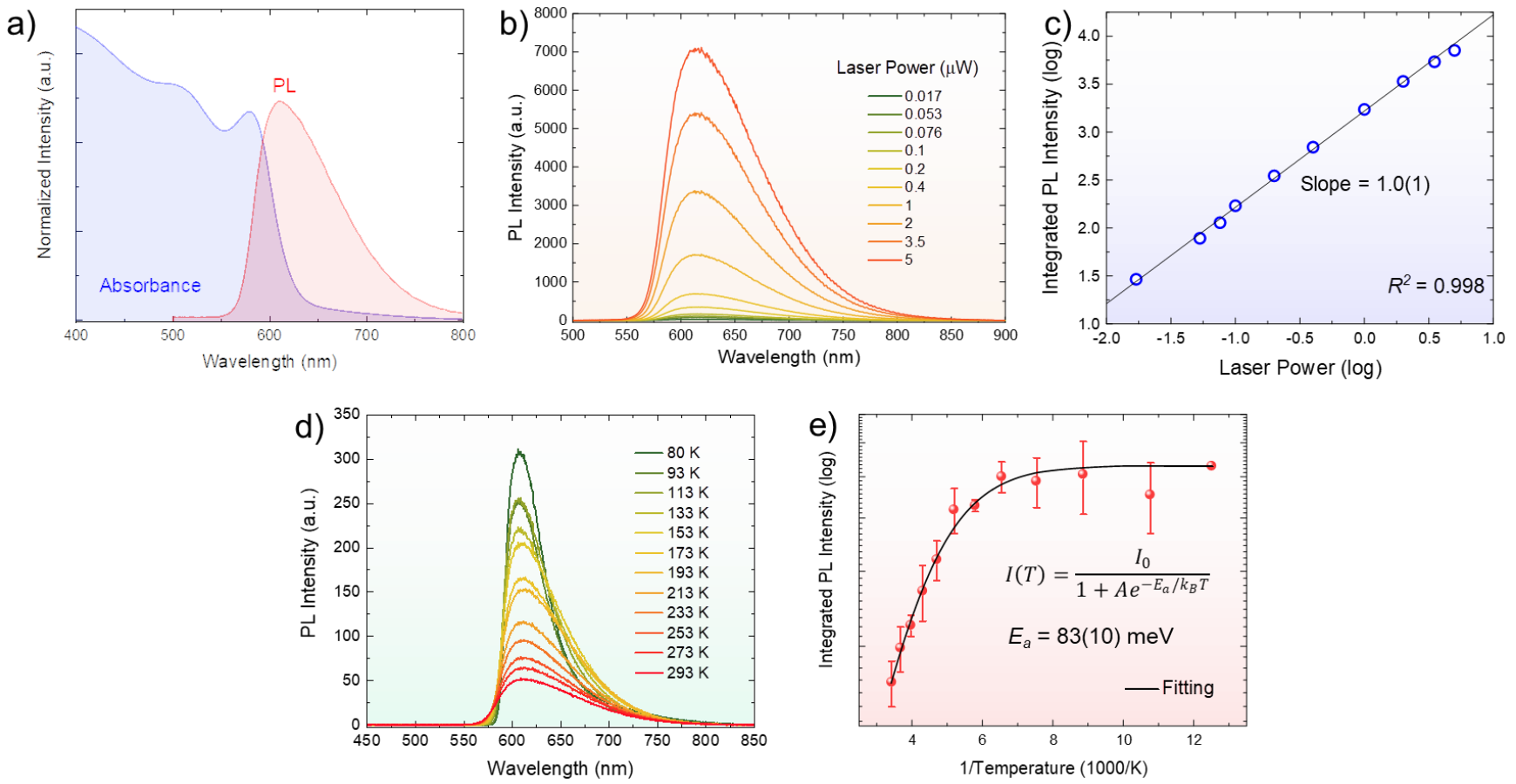

Figure 5. a) Room temperature UV-visible absorbance and photoluminescence (PL) spectra of ImEA[SnI $I_{4}$. b) Evolution of the photoluminescence spectrum of ImEA[SnI $\mathrm{S}_{4}$ as a function of laser power, at $293 \mathrm{~K}$ excited by $573 \mathrm{~nm}$ wavelength. c) Plot and linear fit of the dependence of photoluminescence intensity of ImEA[SnI 4 ] versus laser power, monitored at $611 \mathrm{~nm}$ wavelength, measured in the range $0.017-5 \mu \mathrm{W}$, at $293 \mathrm{~K}$. d) Temperature-dependent photoluminescence (PL) spectra of single crystal ImEA[SnI 4 ], recorded using a $573 \mathrm{~nm}$ continuous-wave laser beam. d) Temperature-dependent integrated PL intensity of single crystal ImEA[SnI 4 ]. The solid line is a best fit of the experimental data (red circles) to the Arrhenius equation, where $I_{0}$ corresponds to the intensity at 0 $\mathrm{K}, E_{a}$ to the activation energy, and $k_{B}$ to the Boltzmann constant.

The PDOS for the $\mathrm{Pb}$ compound ImEA[PbI $\mathrm{Pb}_{4}$ has similar fea-

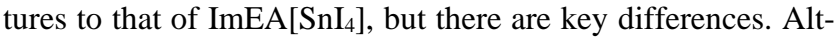
hough the antibonding components of the interactions between the $\mathrm{Pb} 6 \mathrm{~s}^{2}$ and I $5 \mathrm{p}$ orbitals do appear at the valence band maximum, they are not well separated from the non-bonding I $5 \mathrm{p}$ orbitals $(c a .-0.8 \mathrm{eV})$. In contrast, the separation is clear and comparatively large in the $\mathrm{Sn}$ compound. This contributes to the smaller band gap of ImEA[SnI $\left.{ }_{4}\right]$ and reflects the greater availability of the $\mathrm{Sn} 5 \mathrm{~s}^{2}$ electrons for bonding, relative to the $\mathrm{Pb} 6 \mathrm{~s}^{2}$ electrons, which is a consequence of the comparatively low energy of the latter. In other words, the inert pair effect. A further consequence of the greater overlap with the I $5 \mathrm{p}$ orbitals is that the $\mathrm{Sn} 5 \mathrm{~s}^{2}$ electrons would be expected to be more stereochemically active than the $\mathrm{Pb} 6 \mathrm{~s}^{2}$ lone pairs. This assertion is borne out by X-ray structure discussion above.

Interestingly, the near-edge regions of the conduction bands of both $\operatorname{ImEA}\left[\mathrm{SnI}_{4}\right]$ and $\mathrm{ImEA}\left[\mathrm{PbI}_{4}\right]$ feature significant contributions from the conjugated aromatic dication $\operatorname{ImEA}^{2+}$. This raises the possibility of charge transfer from the inorganic to the organic components of these materials and might be expected to endow them with enhanced inter-layer conductivity. Interactions of this type, which led to similar inferences, have precedence in one-dimensional (1D) lead iodide hybrids containing the electron deficient aromatic tropylium ${ }^{62}$ and viologen ${ }^{63}$ templating cations.

Lead-free 2D perovskite solar cell application. The low $E_{a}$ measured for ImEA[SnI $\left.{ }_{4}\right]$ signifies that separation of its photogenerated charge carriers proceeds with comparative ease. In response, $2 \mathrm{D}$ perovskite solar cells adopting the inverted $\mathrm{p}-\mathrm{i}-\mathrm{n}$ architecture were fabricated (Figure 7a; see SI for further details). More specifically, devices consisting of a stack of indium tin oxide (ITO)/poly(3,4-ethylenedioxythiophene): poly(styrene-sulfonate) (PEDOT:PSS, $40 \mathrm{~nm}$ )/ImEA[SnI 4 $(400 \mathrm{~nm}) /[6,6]-$ phenyl-C $\mathrm{C}_{61}$-butyric acid methyl ester (PCBM, $30 \mathrm{~nm}$ )/ bathocuproine (BCP, $7 \mathrm{~nm}$ )/aluminium (Al, $100 \mathrm{~nm})$ was chosen in our study. This configuration was selected because the dopants present in commonly employed hole transporting materials (HTM), such as Spiro-OMeTAD, were found to accelerate the deterioration of tin perovskites. Additionally, the HTM energy levels in n-i-p devices are, generally, not

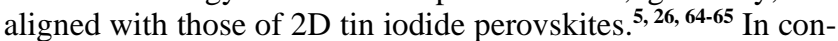
trast, as shown in Figure 7b, the band energies of ImEA[SnI4] align well with those of the electron/hole transporting layers in inverted devices. In particular, the conduction band edge of ImEA $\left[\mathrm{SnI}_{4}\right]$ is determined via ultraviolet photoelectron spectroscopy (UPS) to be $-5.2 \mathrm{eV}$ (Figure 7b), while the band gap is estimated to be ca. $2.02 \mathrm{eV}$ (Figure S10). The HOMO of PEDOT:PSS and LUMO of PCBM are known to be $c a .-5.0 \mathrm{eV}$ and $-4.2 \mathrm{eV}$, respectively. ${ }^{66-68}$ This good alignment promotes efficient interfacial charge transfer in the perovskite solar cell devices. Scanning electron microscopy (SEM) and atomic force microscopy (AFM) images confirm the compactness and smoothness of the perovskite layer (Figures S11 and S12, respectively), while its crystallinity was established with glancing-angle X-ray diffraction (GAXRD; Figure S13).

The optimized precursor concentration for spin-coating solutions of ImEA[SnI 4 , in 7:3 mixtures of DMF and DMSO, was found to be $0.75 \mathrm{M}$. Details of concentration-dependent device performance parameters, average device performances, and corresponding characterization data can be found in Tables 

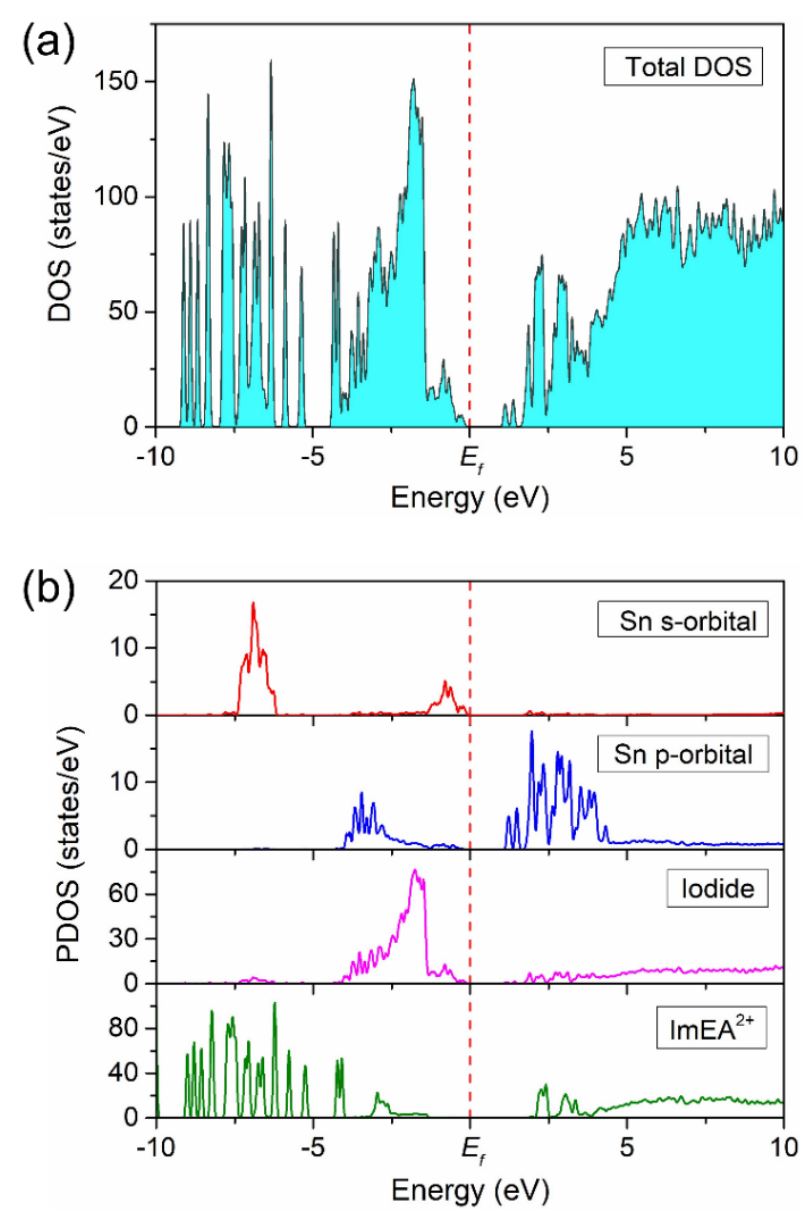

Figure 6. DFT calculated a) total density of states (DOS) and b) projected density of states (PDOS) for $\operatorname{ImEA}\left[\mathrm{SnI}_{4}\right]$, where $E_{f}$ corresponds to the Fermi level.

S27-S29. Additionally, statistical representations of individual photovoltaic parameters of 10 devices, based on $\operatorname{ImEA}\left[\mathrm{SnI}_{4}\right]$, which confirm the reproducibility of the device fabrication process, are depicted in Figures 7c and S14a-d, and summarized in Table S28. Meanwhile, current density-voltage $(J-V)$ characteristics of the best device fabricated from $\mathrm{ImEA}\left[\mathrm{SnI}_{4}\right]$ are presented in Figure 7d and Table 2.

In our devices, the forward scan of current as a function of potential, under 1 sun white light irradiation, was found to be almost identical with the reverse scan (Figure 7d, Table 2). This lack of hysteresis is indicative of minimal ion migration within $\operatorname{ImEA}\left[\mathrm{SnI}_{4}\right]$, which can be attributed to the bulky and dicationic nature of $\mathrm{ImEA}^{2+} .{ }^{19}, 69$ This conclusion is supported by poling measurements conducted on thin-film lateral devices featuring interdigitated electrodes (see Figure S15 and SI for

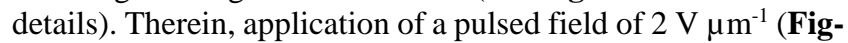
ure S16) induces an open circuit voltage inside the material of about $200 \mathrm{mV}$ (Figure S17). This resembles the switchable photovoltaic behavior reported for 3D lead halide perovskites, in which an intrinsic $\mathrm{p}-\mathrm{n}$ junction is born from the charge imbalance created by ion migration. However, this effect is less reversible in $\mathrm{ImEA}\left[\mathrm{SnI}_{4}\right]$ than it is for $3 \mathrm{D}$ lead halide perovskites, ${ }^{70}$ a fact that can be attributed to slower migration of the organic cations in the former due to their larger size and greater charge. ${ }^{19,69}$
Table 2. Selected photovoltaic parameters of the best perform-

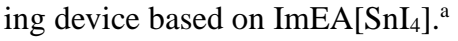

$\begin{array}{ccccc}\begin{array}{c}\text { Scan } \\ \text { direction }\end{array} & \begin{array}{c}V_{o c} \\ (\mathrm{mV})\end{array} & \begin{array}{c}J_{s c} \\ \left(\mathrm{~mA} \mathrm{~cm}^{-2}\right)\end{array} & \begin{array}{c}\mathrm{FF} \\ (\%)\end{array} & \begin{array}{c}\text { PCE } \\ (\%)\end{array} \\ \text { Reverse } & 446 & 9.12 & 55.62 & 2.26 \\ \text { Forward } & 431 & 9.12 & 56.19 & 2.21\end{array}$

${ }^{\mathrm{a}} V_{o c}, J_{s c}, \mathrm{FF}, \mathrm{PCE}$ correspond to open-circuit voltage, short-circuit current density, fill-factor, and power conversion efficiency, respectively.

The best performing PV cell based on $\operatorname{ImEA}\left[\mathrm{SnI}_{4}\right]$ supplied a short-circuit current density $\left(J_{s c}\right)$ as high as $9.12 \mathrm{~mA} \mathrm{~cm}^{-2}$. This represents a more than two-fold improvement over the overwhelming majority of $\mathrm{Pb}$-based $2 \mathrm{D}$ perovskite solar cells. ${ }^{17-18 \text {, }}$ 25,71-72 This includes its Pb-based counterpart $\operatorname{ImEA}\left[\mathrm{PbI}_{4}\right]\left(J_{s c}=\right.$ $3.94 \mathrm{~mA} \mathrm{~cm}^{-2}$ ) and the best performing PV device utilizing a pure 2D solar absorber documented thus far, which contains (3$\mathrm{APN})_{2}\left[\mathrm{PbI}_{4}\right]$, has a PCE of $3.39 \%$, and a $J_{s c}$ of only $5.73 \mathrm{~mA}$ $\mathrm{cm}^{-2} \cdot{ }^{18}$ Such superior charge collection in $\operatorname{ImEA}\left[\mathrm{SnI}_{4}\right]$, relative to $\mathrm{Pb}$-based 2D perovskites, is primarily due to the better visible light absorption capabilities of iodostannates. As shown in the incident photon-to-current efficiency (IPCE) spectrum of the best performing device (Figure 7e), the device absorption onset extends to $650 \mathrm{~nm}$, which correlates with the UV-Vis absorption band edge of the material. In contrast, $\mathrm{Pb}$-based $2 \mathrm{D}$ perovskite solar cells typically feature absorption onsets $<600 \mathrm{~nm}$. ${ }^{17}$ $18,25,71-72$

An additional likely contributor to the comparatively high efficiency of current generation in our devices is the low exciton binding energy in $\operatorname{ImEA}\left[\mathrm{SnI}_{4}\right]$, approximated by $E_{\mathrm{a}}$. As mentioned above, this is believed to be associated with the very short separation between the inorganic layers of the material and the polarizability of the aromatic templating cations, $\mathrm{ImEA}^{2+}$. This is reflected by IPCE values of up to $70 \%$. For comparison, a value of $65 \%$ was reported for a device based on $\mathrm{Bn}_{2}\left[\mathrm{SnI}_{4}\right]$, which features larger iodostannate sheet spacing (I $\cdots$ I closest contacts of $8.077 \AA$ ). ${ }^{26}$ Thus, our results indicate that modulation of the distance between the inorganic layers can play a pivotal role in further mitigating the efficiency limits of 2D metal halide perovskites. When coupled with a good opencircuit voltage $\left(V_{o c}\right)$ of $55 \%$ and a fill-factor of over $400 \mathrm{mV}$, the best performing PV device containing $\operatorname{ImEA}\left[\mathrm{SnI}_{4}\right]$ displayed a PCE of $2.26 \%$. (See Figure 7c for the histogram of device PCEs.) This value is nearly identical to that of the only other reported 2D Sn-based perovskite solar cell (2.35\%), and makes our device one of the most efficient fabricated from pure 2D group 14 metal halide perovskites. ${ }^{\mathbf{1 6}, \mathbf{2 4 - 2 5 , 6 6}}$

\section{CONCLUSION}

In conclusion, we have disclosed the first two examples of "3 $\times 3$ " (110)-oriented 2D tin iodide perovskites. Isomeric imidazolium-based dications were used to template these materials. The presence of two endocyclic $\mathrm{N}$-atoms in the imidazolium core, both of which have supramolecular interactions with the tin iodide framework, plays a pivotal role in inducing formation of the corrugated structure. This is deduced from the observation of more common (100)-type 2D perovskite structures for templating dications containing pyridinium cores, irrespective 
a)

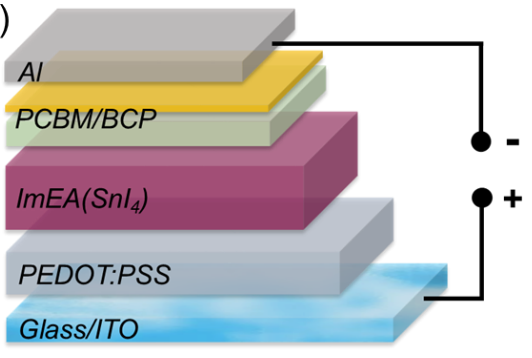

b)

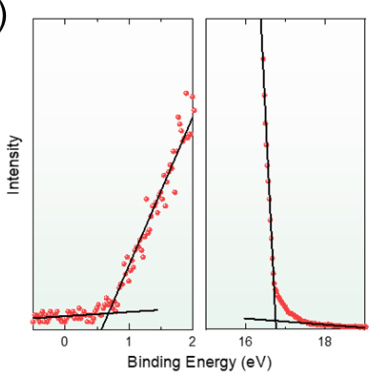

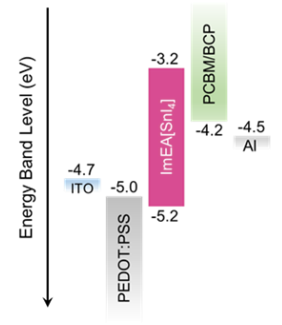

e)

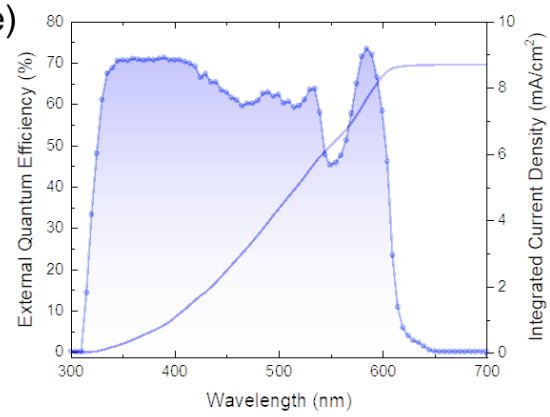

Figure 7. a) Schematic representation of the perovskite solar cell configuration employed in this study. b) Ultraviolet photoelectron spectroscopy (UPS) spectrum of a thin film of ImEA[SnI 4 , plus a band energy diagram of the solar cell that is comprised of $\operatorname{ImEA}\left[\mathrm{SnI}_{4}\right]$, the charge transport materials, and the electrodes. Extrapolation of the spectral offset allows estimation of the material's valence band energy level, and the band gap was extracted from the Tauc Plot of the thin film's absorption spectrum (Figure S11). c) Statistical representations of power conversion efficiency $(\eta)$ measured for 10 photovoltaic devices containing the solar absorber $\operatorname{ImEA}\left[\mathrm{SnI}_{4}\right]$. d) Photovoltaic current density-voltage $(J-V)$ characteristics of the best performing solar cell fabricated using $\operatorname{ImEA}\left[\mathrm{SnI}_{4}\right]$ as the solar absorber, under white light irradiation (1 sun; AM $\left.1.5 \mathrm{G}\right)$. e) External quantum efficiency (EQE) spectrum of the best performing solar cell, which displays an integrated short-circuit current density $\left(J_{s c}\right)$ of $8.65 \mathrm{~mA} \mathrm{~cm}{ }^{-2}$.

Table 3. Photovoltaic performances of best performing pure 2D perovskite solar cells.

\begin{tabular}{|c|c|c|}
\hline Comp & Device architecture & PCE \\
\hline $\mathrm{Bn}_{2}\left[\mathrm{SnI}_{4}\right]^{\alpha}$ & $\begin{array}{l}\mathrm{FTO} / \mathrm{c}-\mathrm{TiO}_{2} / \mathrm{meso}^{-\mathrm{TiO}_{2}} / 2 \mathrm{D} \\
\mathrm{PVK} / \mathrm{Au}\end{array}$ & $2.35 \%$ \\
\hline $\operatorname{ImEA}\left[\mathrm{SnI}_{4}\right]^{\beta}$ & $\begin{array}{l}\text { ITO/PEDOT:PSS/2D } \\
\text { PVK/PCBM/BCP/Al }\end{array}$ & $\begin{array}{l}2.26 \\
\% *\end{array}$ \\
\hline $\mathrm{BdA}\left[\mathrm{PbI}_{4}\right]^{\gamma}$ & 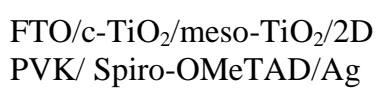 & $1.08 \%$ \\
\hline $\mathrm{HA}\left[\mathrm{PbI}_{4}\right]^{\delta}$ & $\begin{array}{l}\text { ITO/PEDOT:PSS/2D } \\
\text { PVK/PCBM/Al }\end{array}$ & 1.13 \\
\hline$(\mathrm{POPA})_{2}\left[\mathrm{PbI}_{4}\right]^{\varepsilon}$ & $\begin{array}{l}\text { ITO/PEDOT:PSS/2D } \\
\text { PVK/Ag }\end{array}$ & $1.38 \%$ \\
\hline $\operatorname{ImEA}\left[\mathrm{PbI}_{4}\right]^{\beta}$ & 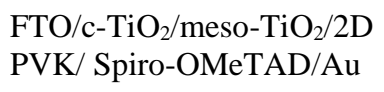 & $1.83 \%$ \\
\hline$(3-\mathrm{APN})_{2}\left[\mathrm{PbI}_{4}\right]^{\zeta}$ & $\begin{array}{l}\text { ITO/NiOx/2D } \\
\text { PVK/PCBM/Ag }\end{array}$ & $3.39 \%$ \\
\hline
\end{tabular}

${ }^{\alpha}$ benzimidazolium, ${ }^{26} \quad{ }^{\beta} 1$-(2-ammonioethyl)-1H-imidazol-3ium, ${ }^{25}{ }^{\gamma}$ Butane-1,4-diaminium, ${ }^{72}{ }^{8}$ histammonium, ${ }^{28}{ }^{8} 3$-(pyren2-yloxy) propan-1-aminium, ${ }^{17}$ ל2-cyanoethan-1-aminium, ${ }^{18}$ *This work.

of the position of the 2-ethylammonium substituent. In addition, the higher tendency of the $5 \mathrm{~s}^{2}$ lone pairs of $\mathrm{Sn}^{2+}$ ions to express stereoactivity relative to the $6 \mathrm{~s}^{2}$ electrons of $\mathrm{Pb}^{2+}$ renders the corresponding iodostannate lattice more prone to corrugation. This is inferred from the broader distribution of metal halide bond distances and the larger off-center displacements relative to their 2D haloplumbate congeners.

The very short inorganic layer separation in $\operatorname{ImEA}\left[\mathrm{SnI}_{4}\right]$ (I $\cdots I$ contacts as small as $4.174 \AA$ ), as a consequence of the compactness of the dication, combines with the polarizable nature of the imidazolium moiety to yield an exciton activation energy $\left(E_{a}\right)$ as low as $83(10) \mathrm{meV}$. When used as a solar absorber, these features allow harvest of short-circuit current densities $\left(J_{s c}\right)$ of more than $9 \mathrm{~mA} \mathrm{~cm}{ }^{-2}$. Superior charge collection in $\operatorname{ImEA}\left[\mathrm{SnI}_{4}\right]$, compared to pure $2 \mathrm{D} \mathrm{Pb}$-halide perovskites, is attributed to its comparatively low energy light absorption onset of $c a .650 \mathrm{~nm}$. In addition, relative to previously reported solar cells based on $\mathrm{Bn}_{2}\left[\mathrm{SnI}_{4}\right]$ (I $\cdots$ I contacts of $8.077 \AA$ ), better IPCE conversions of up to $70 \%$ were obtained from $\operatorname{ImEA}\left[\mathrm{SnI}_{4}\right]$, which is attributed to the shorter inorganic layer separation in the latter. This allows access to photovoltaic cells with power conversion efficiencies of $2.26 \%$, which is amongst the highest values reported, so far, for pure 2D metal halide perovskite solar cells.

Thus, this work contributes substantially to the field of lowdimensional perovskites in two respects. Firstly, the impact of systematic tuning of the templating organic cation upon inorganic architecture detailed herein provides insight into the factors (i.e., secondary intermolecular interactions and stereochemical activity of s orbital electron lone pairs) that induce 2D hybrid perovskites featuring specific inorganic lattice fine structures. Secondly, we have provided only the second example of a PV device that employs a pure 2D tin halide perovskite as a solar absorber and shown that it displays an efficiency superior to all, but one, of the many examples of pure $2 \mathrm{D} \mathrm{Pb}$-based 
materials. Given that the improved performance of the iodostannate is tied to its inherently greater light absorption capabilities, we would argue that these materials have greater potential than their more toxic Pb-based congeners. The highly malleable nature of the iodostannate lattice means that molecular design of templating organic cations will be crucial in this process, with inorganic layer separation and intra- and inter-octahedral distortions being particularly important factors in tailoring their optoelectronic performance.

\section{ASSOCIATED CONTENT}

\section{Supporting Information}

Crystal structures of hybrid lead iodide perovskites (cif files).

Experimental procedures, materials synthesis, additional spectra and crystallographic data (pdf).

The Supporting Information is available free of charge on the ACS Publications website.

\section{AUTHOR INFORMATION}

\section{Corresponding Author}

*E-mail: jengland@ntu.edu.sg.

* E-mail:nripan@ntu.edu.sg.

* E-mail: zexiang@ntu.edu.sg.

*E-mail: sudip@iiti.ac.in, sudiphys@gmail.com.

\section{Notes}

The authors declare no competing financial interest. CIF data for associated crystal structures have been deposited in the Cambridge Crystallographic Data Centre under deposition numbers CCDC $1949805-1949812$.

\section{ACKNOWLEDGMENT}

We would like to thank Prof. Subodh G. Mhaisalkar for providing access to the facilities of the Energy Research Institute @ NTU (ERI@N). JE is grateful to NTU for funding (M4081442). SGM, $\mathrm{NM}, \mathrm{BF}, \mathrm{TMK}$, and TJNH would like to acknowledge funding from the Singapore National Research Foundation through the Intra-CREATE Collaborative Program (NRF2018-ITC001-001), Office of Naval Research Global (ONRG-NICOP-N62909-17-12155), and the Competitive Research Program: NRF-CRP142014-03. YL and ZXS would like to acknowledge Ministry of Education of Singapore for the funding through AcRF Tier 1 (ref. RG195/ 17 and RG 156/19). JK and SC acknowledge the fellowship from IIT Indore and computing time from NSCC, Singapore. TJNH would like to acknowledge the Center of High Field NMR Spectroscopy and Imaging (NTU) for the use of their facilities.

\section{REFERENCES}

1. Best Research-Cell Efficiencies, Rev. 03-08-2020 (NREL, 2020); https://www.nrel.gov/pv/assets/pdfs/best-research-cellefficiencies.20200803.pdf.

2. Jiang, Y.; Qiu, L.; Juarez-Perez, E. J.; Ono, L. K.; Hu, Z.; Liu, Z.; Wu, Z.; Meng, L.; Wang, Q.; Qi, Y. Reduction of lead leakage from damaged lead halide perovskite solar modules using self-healing polymer-based encapsulation. Nat. Energy 2019, 4 (7), 585-593

3. Stoumpos, C. C.; Frazer, L.; Clark, D. J.; Kim, Y. S.; Rhim, S. H.; Freeman, A. J.; Ketterson, J. B.; Jang, J. I.; Kanatzidis, M. G. Hybrid germanium iodide perovskite semiconductors: active lone pairs, structural distortions, direct and indirect energy gaps, and strong nonlinear optical properties. J. Am. Chem. Soc. 2015, 137 (21), 6804-6819.

4. Stoumpos, C. C.; Mao, L.; Malliakas, C. D.; Kanatzidis, M. G. Structure-Band Gap Relationships in Hexagonal Polytypes and Low-Dimensional Structures of Hybrid Tin Iodide Perovskites. Inorg. Chem. 2017, 56 (1), 56-73.

5. Ke, W.; Stoumpos, C. C.; Kanatzidis, M. G. "Unleaded" Perovskites: Status Quo and Future Prospects of Tin-Based Perovskite Solar Cells. Adv. Mater. 2019, 31, 1803230.

6. Kumar, M. H.; Dharani, S.; Leong, W. L.; Boix, P. P.; Prabhakar, R. R.; Baikie, T.; Shi, C.; Ding, H.; Ramesh, R.; Asta, M.; Graetzel, M.; Mhaisalkar, S. G.; Mathews, N. Lead-free halide perovskite solar cells with high photocurrents realized through vacancy modulation. Adv. Mater. 2014, 26 (41), 7122 7127.

7. Tai, Q.; Guo, X.; Tang, G.; You, P.; Ng, T. W.; Shen, D.; Cao, J.; Liu, C. K.; Wang, N.; Zhu, Y.; Lee, C. S.; Yan, F. Antioxidant Grain Passivation for Air-Stable Tin-Based Perovskite Solar Cells. Angew. Chem. Int. Ed. 2019, 58 (3), 806-810.

8. Song, T. B.; Yokoyama, T.; Stoumpos, C. C.; Logsdon, J.; Cao, D. H.; Wasielewski, M. R.; Aramaki, S.; Kanatzidis, M. G. Importance of Reducing Vapor Atmosphere in the Fabrication of Tin-Based Perovskite Solar Cells. J. Am. Chem. Soc. 2017, 139 (2), 836-842.

9. Gu, F.; Ye, S.; Zhao, Z.; Rao, H.; Liu, Z.; Bian, Z.; Huang, C. Improving Performance of Lead-Free Formamidinium Tin Triiodide Perovskite Solar Cells by Tin Source Purification. Sol. RRL 2018, 2 (10), 1800136.

10. Gao, W.; Ran, C.; Li, J.; Dong, H.; Jiao, B.; Zhang, L.; Lan, X.; Hou, X.; Wu, Z. Robust Stability of Efficient Lead-Free Formamidinium Tin Iodide Perovskite Solar Cells Realized by Structural Regulation. J. Phys. Chem. Lett. 2018, 9 (24), 69997006.

11. Prasanna, R.; Gold-Parker, A.; Leijtens, T.; Conings, B.; Babayigit, A.; Boyen, H. G.; Toney, M. F.; McGehee, M. D. Band Gap Tuning via Lattice Contraction and Octahedral Tilting in Perovskite Materials for Photovoltaics. J. Am. Chem. Soc. 2017, 139 (32), 11117-11124.

12. Nakamura, T.; Yakumaru, S.; Truong, M. A.; Kim, K.; Liu, J.; Hu, S.; Otsuka, K.; Hashimoto, R.; Murdey, R.; Sasamori, T.; Kim, H. D.; Ohkita, H.; Handa, T.; Kanemitsu, Y.; Wakamiya, A. $\mathrm{Sn}(\mathrm{IV})$-free tin perovskite films realized by in situ $\mathrm{Sn}(0)$ nanoparticle treatment of the precursor solution. Nat. Commun. 2020, 11 (1), 3008.

13. Liu, X.; Wang, Y.; Wu, T.; He, X.; Meng, X.; Barbaud, J.; Chen, H.; Segawa, H.; Yang, X.; Han, L. Efficient and stable tin perovskite solar cells enabled by amorphous-polycrystalline structure. Nat. Commun. 2020, 11 (1), 2678.

14. Jiang, X.; Wang, F.; Wei, Q.; Li, H.; Shang, Y.; Zhou, W.; Wang, C.; Cheng, P.; Chen, Q.; Chen, L.; Ning, Z. Ultra-high open-circuit voltage of tin perovskite solar cells via an electron transporting layer design. Nat. Commun. 2020, 11 (1), 1245.

15. Cheng, Z.; Lin, J. Layered organic-inorganic hybrid perovskites: structure, optical properties, film preparation, patterning and templating engineering. CrystEngComm 2010, 12 (10), 2646-2662.

16. Saparov, B.; Mitzi, D. B. Organic-Inorganic Perovskites: Structural Versatility for Functional Materials Design. Chem. Rev. 2016, 116 (7), 4558-4596.

17. Passarelli, J. V.; Fairfield, D. J.; Sather, N. A.; Hendricks, M. P.; Sai, H.; Stern, C. L.; Stupp, S. I. Enhanced Out-of-Plane Conductivity and Photovoltaic Performance in $n=1$ Layered Perovskites through Organic Cation Design. J. Am. Chem. Soc. 2018, 140 (23), 7313-7323.

18. Li, Y.; Zhao, Y.; Cheng, H.; Zhao, K.; Wang, Z. S. Highly Efficient and Stable Pure Two-Dimensional Perovskite-Based Solar Cells with the 3-Aminopropionitrile Organic Cation. ACS Appl. Mater. Interfaces 2020, 12 (16), 18590-18595.

19. Lin, Y.; Bai, Y.; Fang, Y.; Wang, Q.; Deng, Y.; Huang, J. Suppressed Ion Migration in Low-Dimensional Perovskites. ACS Energy Lett. 2017, 2 (7), 1571-1572. 
20. Huang, Z.; Proppe, A. H.; Tan, H.; Saidaminov, M. I.; Tan, F.; Mei, A.; Tan, C.-S.; Wei, M.; Hou, Y.; Han, H.; Kelley, S. O.; Sargent, E. H. Suppressed Ion Migration in Reduced-Dimensional Perovskites Improves Operating Stability. ACS Energy Lett. 2019, 4 (7), 1521-1527.

21. Mao, L.; Stoumpos, C. C.; Kanatzidis, M. G. Two-Dimensional Hybrid Halide Perovskites: Principles and Promises. J. Am. Chem. Soc. 2019, 141 (3), 1171-1190.

22. Smith, M. D.; Connor, B. A.; Karunadasa, H. I. Tuning the Luminescence of Layered Halide Perovskites. Chem. Rev. 2019, $119(5), 3104-3139$.

23. Cao, D. H.; Stoumpos, C. C.; Farha, O. K.; Hupp, J. T.; Kanatzidis, M. G. 2D Homologous Perovskites as Light-Absorbing Materials for Solar Cell Applications. J. Am. Chem. Soc. 2015, 137 (24), 7843-7850.

24. Koh, T. M.; Shanmugam, V.; Schlipf, J.; Oesinghaus, L.; Muller-Buschbaum, P.; Ramakrishnan, N.; Swamy, V.; Mathews, N.; Boix, P. P.; Mhaisalkar, S. G. Nanostructuring Mixed-Dimensional Perovskites: A Route Toward Tunable, Efficient Photovoltaics. Adv. Mater. 2016, 28 (19), 3653-3661.

25. Febriansyah, B.; Koh, T. M.; Lekina, Y.; Jamaludin, N. F.; Bruno, A.; Ganguly, R.; Shen, Z. X.; Mhaisalkar, S. G.; England, J. Improved Photovoltaic Efficiency and Amplified Photocurrent Generation in Mesoporous $n=1$ Two-Dimensional Lead-Iodide Perovskite Solar Cells. Chem. Mater. 2019, 31 (3), 890-898.

26. Zimmermann, I.; Aghazada, S.; Nazeeruddin, M. K. Lead and HTM Free Stable Two-Dimensional Tin Perovskites with Suitable Band Gap for Solar Cell Applications. Angew. Chem. Int. Ed. 2019, 58 (4), 1072-1076.

27. Guan, J.; Tang, Z.; Guloy, A. M. $\alpha-\left[\mathrm{NH}_{3}\left(\mathrm{CH}_{2}\right)_{5} \mathrm{NH}_{3}\right] \mathrm{SnI}_{4}$ : a new layered perovskite structure. Chem. Commun. 1999, $1833-1834$.

28. Mao, L.; Tsai, H.; Nie, W.; Ma, L.; Im, J.; Stoumpos, C. C.; Malliakas, C. D.; Hao, F.; Wasielewski, M. R.; Mohite, A. D.; Kanatzidis, M. G. Role of Organic Counterion in Lead- and Tin-Based Two-Dimensional Semiconducting Iodide Perovskites and Application in Planar Solar Cells. Chem. Mater. 2016, 28 (21), 7781-7792.

29. Febriansyah, B.; Giovanni, D.; Ramesh, S.; Koh, T. M.; Li, Y.; Sum, T. C.; Mathews, N.; England, J. Inducing formation of a corrugated, white-light emitting 2D lead-bromide perovskite via subtle changes in templating cation. J. Mater. Chem. C 2020, 8 (3), 889-893.

30. $\mathrm{Xu}, \quad \mathrm{Z}$; Mitzi, D. B.; Medeiros, D. R $\left[\left(\mathrm{CH}_{3}\right)_{3} \mathrm{NCH}_{2} \mathrm{CH}_{2} \mathrm{NH}_{3}\right] \mathrm{SnI}_{4}$ : A Layered Perovskite with Quaternary/Primary Ammonium Dications and Short Interlayer Iodine-Iodine Contacts. Inorg. Chem. 2003, 42 (5), 1400-1402.

31. Takahashi, Y.; Obara, R.; Nakagawa, K.; Nakano, M.; Tokita, J.; Inabe, T. Tunable Charge Transport in Soluble Organic-Inorganic Hybrid Semiconductors. Chem. Mater. 2007, 19 (25), 6312-6316.

32. Tang, Z.; Guan, J.; Guloy, A. M. Synthesis and crystal structure of new organic-based layered perovskites with 2,2'-biimidazolium cations. J. Mater. Chem. 2001, 11 (2), 479-482.

33. Zimmermann, I.; Keene, T. D.; Hauser, J.; Decurtins, S.; Liu, S. X. Crystal structures of isotypic poly[bis-(benz-imid-azolium) [tetra- $\mu$-iodido-stannate(II) $]]$ and poly[bis-(5,6di-fluoro-benzimidazolium) [tetra- $\mu$-iodido-stannate(II)]]. Acta Crystallogr. Sect. E Struct. Rep. Online 2014, 70 (Pt 10), 178-182.

34. Febriansyah, B.; Lekina, Y.; Ghosh, B.; Harikesh, P. C.; Koh, T. M.; Li, Y.; Shen, Z.; Mathews, N.; England, J. Molecular Engineering of Pure 2D Lead-Iodide Perovskite Solar Absorbers Displaying Reduced Band Gaps and Dielectric Confinement. ChemSusChem 2020, 13 (10), 2693-2701.

35. Febriansyah, B.; Borzda, T.; Cortecchia, D.; Neutzner, S.; Folpini, G.; Koh, T. M.; Li, Y.; Mathews, N.; Petrozza, A.; England, J. Metal Coordination Sphere Deformation Induced Highly Stokes-Shifted, Ultra Broadband Emission in 2D
Hybrid Lead-Bromide Perovskites and Investigation of Its Origin. Angew. Chem. Int. Ed. 2020, 59 (27), 10791-10796.

36. Seshadri, R. Visualizing lone pairs in compounds containing heavier congeners of the carbon and nitrogen group elements. Proc. Indian Acad. Sci. (Chem. Sci.) 2001, 113 (5\& 6), $487-$ 496.

37. Bersuker, I. B. Pseudo-Jahn-teller effect--a two-state paradigm in formation, deformation, and transformation of molecular systems and solids. Chem. Rev. 2013, 113 (3), 1351-1390.

38. Walsh, A.; Payne, D. J.; Egdell, R. G.; Watson, G. W. Stereochemistry of post-transition metal oxides: revision of the classical lone pair model. Chem. Soc. Rev. 2011, 40 (9), $4455-$ 4463.

39. Watson, G. W.; Parker, S. C.; Kresse, G. Ab initio calculation of the origin of the distortion of $\alpha$-PbO. Phys. Rev. B 1999, 59 (13), 8481-8486.

40. Waghmare, U. V.; Spaldin, N. A.; Kandpal, H. C.; Seshadri, R. First-principles indicators of metallicity and cation off-centricity in the IV-VI rocksalt chalcogenides of divalent $\mathrm{Ge}, \mathrm{Sn}$, and Pb. Phys. Rev. B 2003, 67 (12), 125111.

41. Brown, I. D. Bond valence as an aid to understanding the stereochemistry of $\mathrm{O}$ and $\mathrm{F}$ complexes of $\mathrm{Sn}(\mathrm{II}), \mathrm{Sb}(\mathrm{III}), \mathrm{Te}(\mathrm{IV})$, I(V) and Xe(VI). J. Solid State Chem. 1974, 11 (3), 214-233.

42. Fabini, D. H.; Seshadri, R.; Kanatzidis, M. G. The underappreciated lone pair in halide perovskites underpins their unusual properties. MRS Bull. 2020, 45 (6), 467-477.

43. Wang, S.; Mitzi, D. B.; Feild, C. A.; Guloy, A. Synthesis and Characterization of $\left[\mathrm{NH}_{2} \mathrm{C}(\mathrm{I}): \mathrm{NH}_{2}\right]_{3} \mathrm{MI}_{5}(\mathrm{M}=\mathrm{Sn}, \mathrm{Pb})$ : Stereochemical Activity in Divalent Tin and Lead Halides Containing Single <110> Perovskite Sheets. J. Am. Chem. Soc. 1995, 117 (19), 5297-5302

44. Laurita, G.; Fabini, D. H.; Stoumpos, C. C.; Kanatzidis, M. G.; Seshadri, R., Chemical tuning of dynamic cation off-centering in the cubic phases of hybrid tin and lead halide perovskites. Chem. Sci. 2017, 8 (8), 5628-5635.

45. Wheeler, R. A.; Kumar, P. N. V. P. Stereochemically active or inactive lone pair electrons in some six-coordinate, group 15 halides. J. Am. Chem. Soc. 1992, 114 (12), 4776-4784.

46. Atanasov, M.; Reinen, D. Predictive Concept for Lone-Pair Distortions - DFT and Vibronic Model Studies of $\mathrm{AX}_{\mathrm{n}}{ }^{-(\mathrm{n}-3)}$ Molecules and Complexes (A $=\mathrm{N}^{\mathrm{III}}$ to $\mathrm{Bi}^{\mathrm{III}} ; \mathrm{X}=\mathrm{F}^{-\mathrm{I}}$ to $\mathrm{I}^{-\mathrm{I}} ; \mathrm{n}=$ 3-6). J. Am. Chem. Soc. 2002, 124 (23), 6693-6705.

47. Walsh, A.; Watson, G. W. Influence of the Anion on Lone Pair Formation in $\mathrm{Sn}$ (II) Monochalcogenides: A DFT Study. $J$. Phys. Chem. B 2005, 109 (40), 18868-18875.

48. Phuyal, D.; Safdari, M.; Pazoki, M.; Liu, P.; Philippe, B.; Kvashnina, K. O.; Karis, O.; Butorin, S. M.; Rensmo, H.; Edvinsson, T.; Kloo, L.; Gardner, J. M. Electronic Structure of Two-Dimensional Lead(II) Iodide Perovskites: An Experimental and Theoretical Study. Chem. Mater. 2018, 30 (15), 4959-4967.

49. Knutson, J. L.; Martin, J. D.; Mitzi, D. B. Tuning the Band Gap in Hybrid Tin Iodide Perovskite Semiconductors Using Structural Templating. Inorg. Chem. 2005, 44 (13), 4699-4705.

50. Dohner, E. R.; Hoke, E. T.; Karunadasa, H. I. Self-assembly of broadband white-light emitters. J. Am. Chem. Soc. 2014, 136 (5), 1718-1721.

51. Mao, L.; Wu, Y.; Stoumpos, C. C.; Wasielewski, M. R.; Kanatzidis, M. G. White-Light Emission and Structural Distortion in New Corrugated Two-Dimensional Lead Bromide Perovskites. J. Am. Chem. Soc. 2017, 139 (14), 5210-5215.

52. Chen, Q.; De Marco, N.; Yang, Y.; Song, T.-B.; Chen, C.-C.; Zhao, H.; Hong, Z.; Zhou, H.; Yang, Y. Under the spotlight: The organic-inorganic hybrid halide perovskite for optoelectronic applications. Nano Today 2015, 10 (3), 355-396.

53. Tao, S.; Schmidt, I.; Brocks, G.; Jiang, J.; Tranca, I.; Meerholz, K.; Olthof, S. Absolute energy level positions in tin- and leadbased halide perovskites. Nat. Commun. 2019, 10 (1), 2560.

54. Pazoki, M.; Edvinsson, T. Metal replacement in perovskite solar cell materials: chemical bonding effects and optoelectronic properties. Sustain. Energy \& Fuels 2018, 2 (7), 1430-1445. 
55. Mitzi, D. B. Synthesis, Crystal Structure, and Optical and Thermal Properties of $\left(\mathrm{C}_{4} \mathrm{H}_{9} \mathrm{NH}_{3}\right)_{2} \mathrm{MI}_{4}(\mathrm{M}=\mathrm{Ge}, \mathrm{Sn}, \mathrm{Pb})$. Chem. Mater. 1996, 8 (3), 791-800.

56. Lanzetta, L.; Marin-Beloqui, J. M.; Sanchez-Molina, I.; Ding, D.; Haque, S. A. Two-Dimensional Organic Tin Halide Perovskites with Tunable Visible Emission and Their Use in LightEmitting Devices. ACS Energy Lett. 2017, 2 (7), 1662-1668.

57. Smith, M. D.; Karunadasa, H. I. White-Light Emission from Layered Halide Perovskites. Acc. Chem. Res. 2018, 51 (3), 619-627.

58. Papavassiliou, G. C.; Koutselas, I. B.; Terzis, A.; Whangbo, M.-H. Structural and electronic properties of the natural quantum-well system $\left(\mathrm{C}_{6} \mathrm{H}_{5} \mathrm{CH}_{2} \mathrm{CH}_{2} \mathrm{NH}_{3}\right)_{2} \mathrm{SnI}_{4}$. Solid State Commun. 1994, 91 (9), 695-698.

59. Hong, X.; Ishihara, T.; Nurmikko, A. V., Dielectric confinement effect on excitons in $\mathrm{PbI}_{4}$-based layered semiconductors. Phys. Rev. B 1992, 45 (12), 6961-6964.

60. Huang, L.-y.; Lambrecht, W. R. L. Electronic band structure, phonons, and exciton binding energies of halide perovskites $\mathrm{CsSnCl}_{3}, \mathrm{CsSnBr}_{3}$, and $\mathrm{CsSnI}_{3}$. Phys. Rev. B 2013, 88 (16), 165203.

61. Tanaka, K.; Kondo, T. Bandgap and exciton binding energies in lead-iodide-based natural quantum-well crystals. Sci. Tech. Adv. Mater. 2004, 4 (6), 599-604.

62. Maughan, A. E.; Kurzman, J. A.; Neilson, J. R. Hybrid inorganic-organic materials with an optoelectronically active aromatic cation: $\left(\mathrm{C}_{7} \mathrm{H}_{7}\right)_{2} \mathrm{SnI}_{6}$ and $\mathrm{C}_{7} \mathrm{H}_{7} \mathrm{PbI}_{3}$. Inorg. Chem. 2015, 54 (1), 370-8.

63. Febriansyah, B.; Koh, T. M.; John, R. A.; Ganguly, R.; Li, Y.; Bruno, A.; Mhaisalkar, S. G.; England, J. Inducing Panchromatic Absorption and Photoconductivity in Polycrystalline Molecular 1D Lead-Iodide Perovskites through $\pi$-Stacked Viologens. Chem. Mater. 2018, 30 (17), 5827-5830.

64. Wang, R.; Wang, J.; Tan, S.; Duan, Y.; Wang, Z.-K.; Yang, Y., Opportunities and Challenges of Lead-Free Perovskite Optoelectronic Devices. Trends in Chemistry 2019, 1 (4), 368-379.
65. Jung, M.-C.; Raga, S. R.; Qi, Y. Properties and solar cell applications of $\mathrm{Pb}$-free perovskite films formed by vapor deposition. RSC Adv. 2016, 6 (4), 2819-2825.

66. Chen, C.-C.; Bae, S.-H.; Chang, W.-H.; Hong, Z.; Li, G.; Chen, Q.; Zhou, H.; Yang, Y. Perovskite/polymer monolithic hybrid tandem solar cells utilizing a low-temperature, full solution process. Mater. Horiz. 2015, 2 (2), 203-211.

67. Yu, J. C.; Hong, J. A.; Jung, E. D.; Kim, D. B.; Baek, S. M.; Lee, S.; Cho, S.; Park, S. S.; Choi, K. J.; Song, M. H. Highly efficient and stable inverted perovskite solar cell employing PEDOT:GO composite layer as a hole transport layer. Sci. Rep. 2018, $8(1), 1070$.

68. Dong, H.; Wu, Z.; Xia, B.; Xi, J.; Yuan, F.; Ning, S.; Xiao, L.; Hou, X., Modified deposition process of electron transport layer for efficient inverted planar perovskite solar cells. Chem. Commun. 2015, 51 (43), 8986-9.

69. Xiao, X.; Dai, J.; Fang, Y.; Zhao, J.; Zheng, X.; Tang, S.; Rudd, P. N.; Zeng, X. C.; Huang, J. Suppressed Ion Migration along the In-Plane Direction in Layered Perovskites. ACS Energy Lett. 2018, 3 (3), 684-688.

70. Xiao, Z.; Yuan, Y.; Shao, Y.; Wang, Q.; Dong, Q.; Bi, C.; Sharma, P.; Gruverman, A.; Huang, J. Giant switchable photovoltaic effect in organometal trihalide perovskite devices. Nat. Mater. 2014, 14 (2), 193-198.

71. Zhang, F.; Kim, D. H.; Lu, H.; Park, J. S.; Larson, B. W.; Hu, J.; Gao, L.; Xiao, C.; Reid, O. G.; Chen, X.; Zhao, Q.; Ndione, P. F.; Berry, J. J.; You, W.; Walsh, A.; Beard, M. C.; Zhu, K. Enhanced Charge Transport in 2D Perovskites via Fluorination of Organic Cation. J. Am. Chem. Soc. 2019, 141 (14), 5972 5979.

72. Safdari, M.; Svensson, P. H.; Hoang, M. T.; Oh, I.; Kloo, L.; Gardner, J. M. Layered 2D alkyldiammonium lead iodide perovskites: synthesis, characterization, and use in solar cells. $J$. Mater. Chem. A 2016, 4 (40), 15638-15646. 


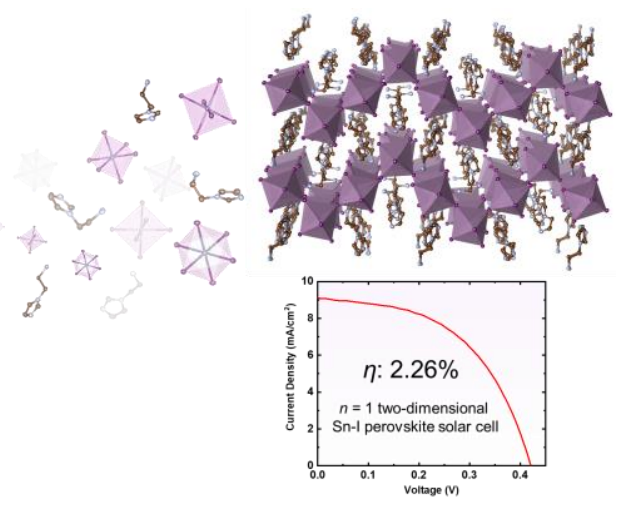

